This document is confidential and is proprietary to the American Chemical Society and its authors. Do not copy or disclose without written permission. If you have received this item in error, notify the sender and delete all copies.

\title{
How the presence of hemin affects the expression of all iron-uptake pathways in Pseudomonas aeruginosa cells
}

\begin{tabular}{|r|l|}
\hline Journal: & ACS Infectious Diseases \\
\hline Manuscript ID & id-2021-00525v.R2 \\
\hline Manuscript Type: & Article \\
\hline Author: & n/a \\
\hline Complete List of Authors: & $\begin{array}{l}\text { Normant, Vincent; Université de Strasbourg, } \\
\text { Kuhn, Lauriane; Institut de Biologie Moléculaire et Cellulaire, Plateforme } \\
\text { Proteomique Strasbourg - Esplanade } \\
\text { Munier, Mathilde; CNRS, UMR7242 } \\
\text { Hammann, Philippe; Institut de Biologie Moléculaire et Cellulaire, } \\
\text { Plateforme Proteomique Strasbourg - Esplanade } \\
\text { Mislin, Gaetan; CNRS, UMR7242 } \\
\text { Schalk, Isabelle; University of Strasbourg - CNRS, UMR7242 }\end{array}$ \\
\hline
\end{tabular}

\section{SCHOLARONE \\ Manuscripts}




\title{
How the presence of hemin affects the expression of all iron-uptake pathways in Pseudomonas aeruginosa cells
}

\author{
Vincent Normant ${ }^{1,2}$, Lauriane Kuhn ${ }^{3}$, Mathilde MUNIER ${ }^{1,2}$, Philippe Hammann ${ }^{3}$, Gaëtan L. A. \\ Mislin, ${ }^{1,2}$ and Isabelle J. Schalk ${ }^{1,2}{ }^{*}$ \\ ${ }^{1}$ CNRS, UMR7242, UMR7242, ESBS, Bld Sébastien Brant, F-67412 Illkirch, Strasbourg, \\ France \\ ${ }^{2}$ Université de Strasbourg, UMR7242, ESBS, Bld Sébastien Brant, F-67412 Illkirch, \\ Strasbourg, France \\ ${ }^{3}$ Plateforme Proteomique Strasbourg - Esplanade, Institut de Biologie Moléculaire et \\ Cellulaire, CNRS, FR1589, 15 rue Descartes, F-67084 Strasbourg Cedex, France
}

*Lead contact or to whom correspondence should be addressed: isabelle.schalk@unistra.fr.

Keywords: Pseudomonas aeruginosa, iron homeostasis, hemin (heam) uptake, iron uptake, siderophore, outer membrane transporters 


\begin{abstract}
Iron is an essential nutriment for almost all organisms, but this metal is poorly bioavailable. During infection, bacteria access iron from the host by importing either iron or heme. Pseudomonas aeruginosa, a Gram-negative pathogen, secretes two siderophores, pyoverdine (PVD) and pyochelin (PCH), to access iron and is also able to use many siderophores produced by other microorganisms (called xenosiderophores). To access heme, $P$. aeruginosa uses three distinct uptake pathways, named Has, Phu, and Hxu. We previously showed that $P$. aeruginosa expresses the Has and Phu heme uptake systems, as well as the PVD- and PCH-dependent ironuptake pathways, in iron-restricted growth conditions, using proteomic and RT-qPCR approaches. Here, using the same approaches, we show that physiological concentrations of hemin in the bacterial growth medium result in the repression of the expression of the proteins of the PVD- and PCH-dependent iron-uptake pathways, leading to less production of these two siderophores. This indicates that the pathogen adapts its phenotype to use hemin as an iron source rather than produce PVD and $\mathrm{PCH}$ to access iron. Moreover, the presence of both hemin and a xenosiderophore resulted in (i) the strong induction of the expression of the proteins of the added xenosiderophore-uptake pathway, (ii) repression of the PVD- and PCH-dependent iron-uptake pathways, and (iii) no effect on the expression levels of the Has, Phu, or Hxu systems, indicating that bacteria use both xenosiderophores and heme to access iron.
\end{abstract}


Iron is essential for bacterial growth, virulence, and survival. This metal is used as an enzymatic cofactor and is required for many essential processes, such as deoxynucleotide biosynthesis, DNA replication, and respiration. ${ }^{1,2}$ Iron can exist in two different oxidation states in biological systems, the ferric $\left(\mathrm{Fe}^{3+}\right)$ or ferrous $\left(\mathrm{Fe}^{2+}\right)$ forms, both playing an essential role in biological oxidation-reduction processes. In the human body, iron is tightly bound by high-affinity binding proteins, such as transferrin, lactoferrin, or ferritin, to prevent iron access to bacterial pathogens and, consequently, bacterial infections. This mechanism is called "nutritional immunity", 33 However, most iron in the human body is included in heme, an aromatic tetrapyrrole macrocycle (protoporphyrin IX) that chelates one atom of iron. Heme is present in hemoproteins, such as hemoglobin and myoglobin.

The opportunistic human pathogen Pseudomonas aeruginosa is able to express three uptake pathways to access heme from the host as an iron source: the Has (ㅌemin assimilation system), Phu (Pseudomonas heme utilization), and Hxu (Hemopexin utilization) pathways (Figure 1). This requires that $P$. aeruginosa expresses three different outer-membrane transporters to acquire heme from the environment: HasR, PhuR, and HxuA. These three transporters belong to the family of TonB-dependent transporters (TBDTs), as their uptake activity is regulated by the proton motive force of the inner membrane via the inner-membrane protein TonB. ${ }^{4}$ HasR recognizes the HasAp-heme complex at the bacterial cell surface, as HasAp is a hemophore protein synthesized by $P$. aeruginosa and secreted into the extracellular environment by the HasDEF secretion system to scavenge heme from the environment. ${ }^{5}$ HasAp of $P$. aeruginosa binds heme with a $K_{D}$ of $350 \pm 50 \mathrm{nM}$ affinity and afterwards interacts with HasR at the bacterial cell surface. ${ }^{6}$ Once the HasR-HasAp-heme complex has been formed, heme is transferred from HasAp to the HasR transporter for uptake across the outer membrane. ${ }^{7-9}$ Heme acquisition by the two other outer-membrane transporters, PhuR and HxuA, does not rely on a hemophore protein, as both transporters can directly bind heme. ${ }^{7,8}$ Once in the periplasm, heme 
transported by either HasR, PhuR, or HxuA, interacts with the periplasmic binding protein $\mathrm{PhuT}^{10}$ for transfer to the $\mathrm{ABC}$ transporter PhuUV and uptake across the inner membrane. In the cytoplasm, heme binds to the cytosolic protein $\mathrm{PhuS}^{11}$ and is transferred to the heme oxygenase HemO. The HemO protein cleaves heme to release biliverdin IX isoforms $\beta$ (BIX $\beta$ ) or $\delta(\mathrm{BIX} \delta)$, carbon monoxide $(\mathrm{CO})$, and iron. ${ }^{12,13}$

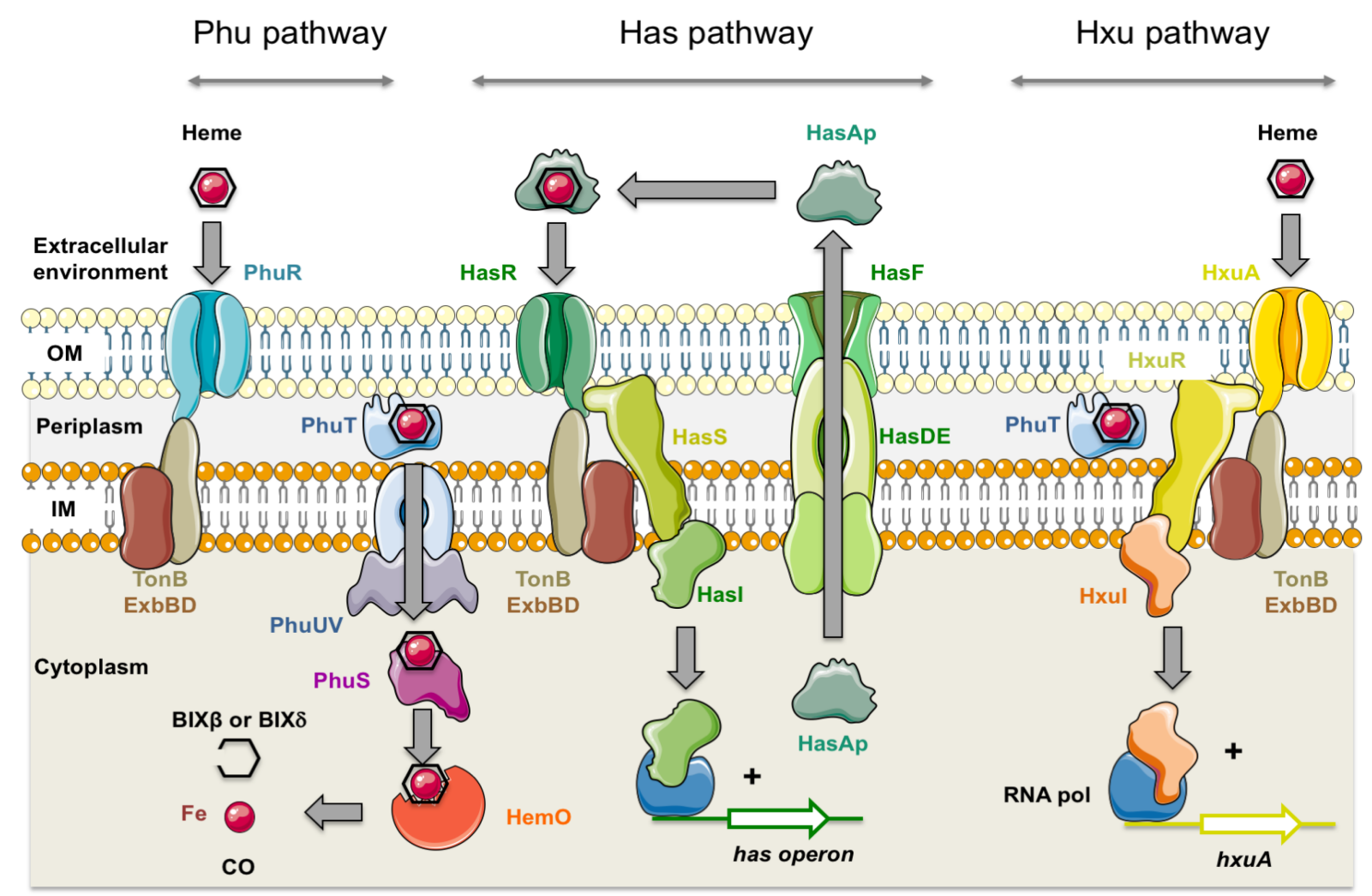

Figure 1. The three heme uptake pathways of $P$. aeruginosa. For more details, see the text in the introduction. OM, outer membrane; IM, inner membrane.

The transcription and expression of the genes of the Has system are regulated by an anti-sigma factor HasS and its corresponding ECF sigma factor HasI. ${ }^{14}$ Once the heme has been transferred from HasAp to the TBDT HasR, the latter interacts through its periplasmic domains with the anti-sigma factor HasS, located in the inner membrane and spanning into the periplasm, to release the sigma transcriptional regulator HasI into the cytoplasm. ${ }^{14}$ HasI then binds to RNA polymerase and upregulates transcription of the hasR, has $A$, and has $S$ genes (has operon). ${ }^{13,14}$ 
Moreover, BIX $\beta$ and BIX $\delta$ post-transcriptionally regulate HasAp translation and consequently the levels of this protein produced by $P$. aeruginosa cells. ${ }^{13,14}$ The HxuA protein is also associated with an anti-sigma protein, HxuR, and an ECF sigma factor, HxuI. However, transcription of the genes of this system is activated in the presence of high concentrations of heme. ${ }^{15}$ Has and Phu systems are both required for efficient utilization of heme in $P$. aeruginosa, with PhuR being the major heme transporter and HasR acting as a high affinity heme sensor of hemin present in the bacterial environment through its interaction with HasA and has an additional role in heme uptake. ${ }^{7,16} \mathrm{HxuA}$ will play a role only at higher heme concentrations. $^{15}$

In parallel with these heme-uptake pathways, $P$. aeruginosa is also able to access ferrous iron via the FeoABC inner-membrane transporter ${ }^{17}$ and ferric iron by producing two siderophores, pyoverdine (PVD) and pyochelin (PCH). ${ }^{18,19}$ Once they have scavenged iron in the bacterial environment, the ferric forms of these two siderophores are transported back across the outer membrane by their specific outer-membrane transporters, FpvA and FpvB for PVD-Fe ${ }^{3+}, 20,21$ and FptA for PCH-Fe ${ }^{3+} \cdot{ }^{22}$ These transporters also belong to the TBDT family and their uptake activity is regulated by the inner-membrane protein TonB. Iron is removed from PVD in the $P$. aeruginosa periplasm by a mechanism involving iron reduction and from $\mathrm{PCH}$ in the bacterial cytoplasm by an unknown mechanism..$^{23,24} P$. aeruginosa can also use xenosiderophores (siderophores produced by other microorganisms) to acquire ferric iron in a siderophore-piracy strategy. ${ }^{25,26}$ Indeed, the genome of $P$. aeruginosa contains various genes encoding TBDTs involved in ferri-xenosiderophore uptake. For example, $P$. aeruginosa is able to import ferric iron using the catechol xenosiderophore enterobactin (ENT) via the TBDTs PfeA and PirA, ${ }^{27-}$ ${ }^{30}$ and vibriobactin via FvbA. ${ }^{31}$ It can also use the hydroxamate siderophores nocardamine (desferrioxamine E or NOCA) and desferrioxamine B (DFOB), transported by FoxA, ${ }^{32,33}$ and ferrichrome, transported by FiuA. ${ }^{34,35} P$. aeruginosa also uses mycobactin and 
carboxymycobactin as xenosiderophores via the outer-membrane transporter FemA, ${ }^{36}$ aerobactin, rhizobactin, and schizokinen by $\mathrm{ChtA},{ }^{37}$ and citrate by $\mathrm{FecA}^{38}$ Finally, catecholamine neurotransmitters, such as dopamine, L-DOPA, epinephrine, and norepinephrine, are able to chelate iron and efficiently import this nutrient into $P$. aeruginosa cells via the outer-membrane transporters PiuA and PirA. ${ }^{26}$

Transcription of all the various genes encoding proteins involved in these ferric iron-uptake pathways via siderophores is regulated either by sigma and anti-sigma factors, two-component systems or transcriptional regulators of the AraC family. ${ }^{36,39,40}$ The bacteria activate the expression of the iron- or heme-uptake pathway(s) that are the most effective, depending on the environment of the bacteria. ${ }^{26}$ Previous proteomic and transcriptomic studies of our group have shown how $P$. aeruginosa adapts the expression of its various iron-uptake pathways to xenosiderophores. ${ }^{26,35,41}$ Moreover, Hijazi et al. showed that the absence of PVD and PCH biosynthesis increases the susceptibility of $P$. aeruginosa to Gallium-protoporphyrin (a toxic analogue of heme), suggesting an increase in has $R$ and $p h u R$ transcription ${ }^{42}$ and a regulatory link between hemin acquisition systems via the HasR and PhuR proteins and PVD and PCH biosynthesis.

An increasing amount of data show that siderophores can be used to import antibiotics into bacteria in a Trojan-horse strategy: antibiotics are covalently attached to siderophores and transported into the pathogens during the ferric-siderophores uptake process. ${ }^{43-45}$ Such a strategy increases the capacity of antibiotics to cross the bacterial envelope and accumulate in the bacterial inner space. Cefiderocol, one such siderophore-antibiotic conjugate developed by Shionogi, has been approved by the European Medicine Agency in April 2020 for the treatment of infections due to aerobic Gram-negative organisms. ${ }^{46,47}$ One major bottleneck limiting the development of siderophore-antibiotic conjugates is that bacteria are equipped with several iron uptake strategies, heme and ferri-siderophores uptake pathways. To make vectorization of 
antibiotics by siderophores successful, it is important to understand how bacteria select and synchronize the expression of their different iron import pathways in response to different iron sources. For example, several studies highlighted that multiple $P$. aeruginosa iron uptake mechanisms are active in chronic cystic fibrosis (CF) infection, with heme uptake pathways playing a crucial role in adaptation of $P$. aeruginosa to this host environment. ${ }^{16,48-52}$ Vectorisation of antibiotics by siderophores needs the expression during infections of the uptake pathways target by the siderophore-antibiotic conjugates.

Here, we investigated how a physiological concentration of heme affects the expression of proteins of the various iron- and heme-uptake pathways present in the genome of $P$. aeruginosa using differential proteomic and RT-qPCR approaches. We also tested the effect of the presence of both heme and two catecholate iron chelators $(\mathrm{TCV}$, an iron chelator used for antibiotic vectorisation and ENT, a siderophore produced by E. coli) or heme and two hydroxamate xenosiderophores (NOCA and DFOB both produced by actinomycetes) using the same approaches. The presence of heme alone repressed the expression of the PVD- and PCHdependent iron-uptake pathways and slightly induced the expression of hasR, the TBDT of the has system (the has and phu heme uptake pathways being already strongly expressed in ironrestricted condition without heme $\left.{ }^{26}\right)$. The presence of heme with ENT, TCV, NOCA or DFOB, induced the expression of the corresponding xenosiderophore-dependent iron uptake pathways, the PVD- and PCH-dependent iron-uptake pathways were more strongly repressed than in the presence of heme alone, and the Has and Phu heme uptake pathways have their expression levels not affected by the presence of the tested xenosiderophores compared to the growth of P. aeruginosa in CAA medium. 


\section{RESULTS AND DISCUSSION}

\section{Effect of $0.25 \mu \mathrm{M}$ hemin on the transcription and expression of hasR, phuR, and $h x u A$.}

Previously, we have shown that the growth of $P$. aeruginosa in the absence of hemin in CAA medium (an iron-restricted medium with an iron concentration of approximately $20 \mathrm{nM}^{53}$ induces the expression of proteins of the PVD- and PCH-dependent iron-uptake pathways, as well as HasR and PhuR, with $\log _{2}$ fold changes in their expression of 5.96 and 5.62, respectively, relative to growth in LB medium (Table S1). ${ }^{26}$ These previous data clearly show that HasR and PhuR expression is already strongly induced in iron-starved P. aeruginosa cells (grown in CAA), even if no hemin is present in the bacterial environment (Table S1). In addition, when grown in CAA medium, $P$. aeruginosa also expresses ChtA, the TBDT of the siderophores aerobactin, rhizobactin and schizokinen, ${ }^{37}$ PirA, a ferri-catechol siderophore outer membrane TBDT, two TBDTs for which the siderophore transported is still unknown, encoded by PA0434 and PA3268, and OprC, a TBDT involved in Cu uptake54 (Table S1). Moreover, we have also shown that the presence of xenosiderophores in P. aeruginosa growth media often strongly induces the expression of the proteins of their corresponding uptake pathways. $^{26,32,35,36,41,45}$

Here, we first investigated the effect of $0.25 \mu \mathrm{M}$ hemin on the expression of the TBDT genes hasR, phuR and hxuA, involved in hemin uptake in P. aeruginosa cells, using differential proteomic approaches. The intracellular concentration of hemin in eukaryotic cells is estimated to be between 0.025 and $0.3 \mu \mathrm{M},{ }^{55}$ and the $\mathrm{K}_{\mathrm{D}}$ of HasAp for hemin of $350 \pm 50 \mathrm{nM},{ }^{6}$ leading us to choose the concentration of $0.25 \mu \mathrm{M}$ hemin for our experiments. PAO1 was grown in CAA medium, with or without $0.25 \mu \mathrm{M}$ hemin, for $8 \mathrm{~h}$ and analyzed by differential proteomics (Figure 2). The 8-h cultures were also analyzed by RT-qPCR to follow the transcription of the hasR and phuR, genes (Figure 3). Outer-membrane transporters are very easily detected by proteomic techniques, often better than any other proteins involved in iron acquisition 
pathways. $^{26,32,35,36,41,45}$ Thus, TBDTs can be used as indicators to follow variations in expression of iron-uptake pathways in P. aeruginosa cells.

The addition of $0.25 \mu \mathrm{M}$ hemin to the CAA growth medium resulted in a small additional induction of the expression of HasR in PAO1 cells, with a $\log _{2}$ fold change of 0.93 (Figure 2) and PhuR and HxuA expression was not modified. In addition, we observed no significant changes in the expression of the other genes encoding proteins of these three heme-uptake pathways (presented in Figure 1). RT-qPCR data showed only slight upregulation of transcription for hasR after $8 \mathrm{~h}$ ( $\log _{2}$ fold change of 0.99$)$. In conclusion, the heme-uptake pathways involving HasR and PhuR are already expressed at high levels in iron-restricted conditions (CAA medium), even if no hemin is present in the bacterial environment. ${ }^{26}$ The addition of $0.25 \mu \mathrm{M}$ hemin to CAA growth media has only a minor additional impact on the transcription and expression of $h a s R$ and no effect on $p h u R$ gene transcription. The additional small induction of the transcription of hasR is due to the presence of hemin at $0.25 \mu \mathrm{M}$ and the activation of transcription of the genes of this Has pathway by the anti-sigma and sigma factors HasS and HasI after formation of the HasR-HasAp-hemin complex at the bacterial cell surface. ${ }^{7,56}$ There is no such transcriptional regulation for the Phu pathway and the expression of the Hxu pathway is only activated at higher hemin concentrations ${ }^{15}$ (Figure 1). Moreover, growth assays in CAA medium of PAO1 and $\Delta h a s R \Delta p h u R$ strains showed that the Has and Phu heme-uptake pathways are mostly involved in hemin acquisition at $0.25 \mu \mathrm{M}$ hemin and not the Hxu pathway (Figure S1). Indeed, PAO1 grown in the presence of $0.25 \mu \mathrm{M}$ hemin showed a clear growth stimulation compared to the growth in the absence of hemin. Besides, in the absence of hemin, PAO1 has a similar growth curve as a $\Delta h a s R \Delta p h u R$ mutant in the presence or absence of hemin, indicating that in our growth conditions only the Has and Phu systems are involved in hemin acquisition and not the Hxu pathway. According to Otero-Asman et al., expression of the Hxu pathway is induced at higher hemin $(20 \mu \mathrm{M})$ concentrations and probably 
imports hemin when present at higher concentrations in the bacterial environment. ${ }^{15}$ In the host, during infection, bacteria growth under iron restriction conditions due to the inflammationdependent iron sequestration response, ${ }^{3}$ and in such iron-restricted conditions, the Has and Phu hemin uptake pathways must be expressed and probably not the Hxu pathway. Indeed, gene expression analysis showed that hemin is a critical source of iron during prolonged infection of the CF lung. ${ }^{16,48-52}$
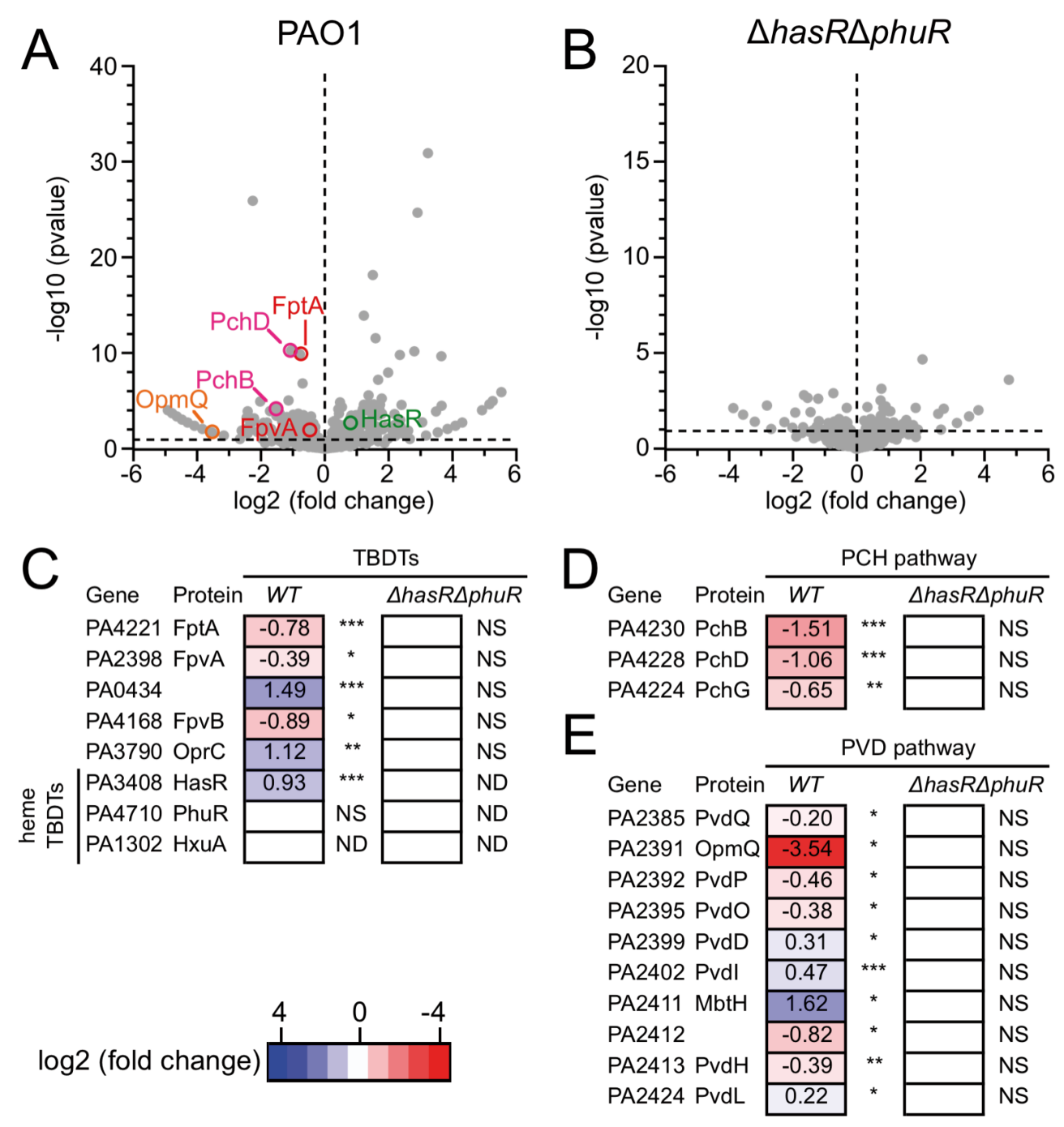

Figure 2: Differential proteomic analyses of $P$. aeruginosa $P$. aeruginosa $P A O 1$ grown in the presence of TCV or TCV and hemin. A. PAO1 cells PAO1 and $\Delta$ hasRAphuR cells grown in CAA minimal medium and in the presence of $0.25 \boldsymbol{\mu M}$ hemin. PAO1 (A) or $\Delta h a s R \Delta p h u R$ (B) strains were grown in CAA medium, with or without hemin $(0.25 \mu \mathrm{M})$, for 8 $\mathrm{h}$ and differential proteomic expression analyzed. The average values measured in CAA medium without hemin were plotted against the average values in CAA supplemented with hemin. C-E. Heat maps of the TBDTs showing a change in their expression (C), as well as 
proteins involved in PCH- (D) and PVD-dependent (E) iron-uptake pathways. In these heat maps, we chose to show HasR, PhuR and HxuA and the proteins for which a change in the level of expression was observed in one of the two conditions analyzed (PAO1 or $\Delta h a s R \Delta p h u R$ ). The darker the shade of blue, the more expression of the protein is induced; the darker the shade of red, the more expression of the protein is repressed. NS: data not significant; ND: not detected (no peptide corresponding to the protein was detected by proteomic); ${ }^{*} p<0.05,{ }^{* *} p$ $<0.01$, and $* * * \mathrm{p}<0.001$

\section{The presence of $0.25 \mu \mathrm{M}$ hemin represses the transcription and expression of genes}

involved in siderophore-dependent iron-uptake pathways. The differential proteomic assay on PAO1 grown in CAA in the absence or presence of $0.25 \mu \mathrm{M}$ hemin described above also showed that the presence of a low concentration of hemin significantly downregulates the expression of genes encoding enzymes involved in $\mathrm{PCH}$ biosynthesis, such as PchB, PchD, and PchG (Figure 2). We observed an equivalent effect for the genes encoding proteins of the PVD pathway, with the outer membrane protein OpmQ of the efflux system PvdRT-OpmQ being the most highly affected, with a $\log _{2}$ decrease in expression of 3.54-fold (PvdRT-OpmQ is involved in the secretion of newly synthesized PVD and PVD following the delivery of iron into $P$. aeruginosa cells $^{57-59}$ ). For the TBDTs involved in the import of ferri-PVD and ferri-PCH, the proteomic data showed a small repression of the expression of the $f p v B, f p v A$, and $f p t A$ genes encoding the outer-membrane transporters of ferri-PVD and ferri-PCH, respectively. We also followed by RT-qPCR changes in the transcription of $f p v A$, fptA, and $p v d J$ (a gene encoding an enzyme involved in PVD biosynthesis), $p c h A$ and $p c h E$ (two genes encoding enzymes involved in PCH biosynthesis), and $p v d S$ and $p c h R$ (two transcriptional regulators of the PVD and PCH pathways, respectively) ${ }^{19}$ (Figure 3). The data showed downregulation of the transcription of $f p v A, f p t A, p v d J, p c h A$, and $p c h E$ in the presence of $0.25 \mu \mathrm{M}$ hemin. The transcription of $p v d S$ and $p c h R$ was less strongly affected by the presence of hemin.

To validate the effect of hemin on the transcription and expression of the various genes and proteins involved in the PVD and PCH pathways, the promoter regions regulating transcription 
of the $p v d S$ and $p c h R$ genes were fused upstream of the $m$ Cherry gene to obtain the following reporter plasmids: pvdSprom::mCherry and pchRprom::mCherry. The $p v d S$ promoter region contains a Fur box, a sequence interacting with the PA2206 LysR regulator and one with the regulator OxyR. ${ }^{60-62}$ Fur is a transcriptional regulator responsible for controlling the intracellular concentration of iron in the bacteria and regulating negatively $p v d S$ transcription. ${ }^{60,63}$ PA2206 and OxyR, both contribute to an effective oxidative stress response in $P$. aeruginosa and are able to activate $p v d S$ transcription under oxidative stress. ${ }^{61,62,64}$ The $p c h R$ promoter region is composed of both a Fur box for transcriptional repression and a PchR box for transcriptional activation (PchR being the transcriptionnal AraC regulator of the $\mathrm{PCH}$ pathway). ${ }^{65}$
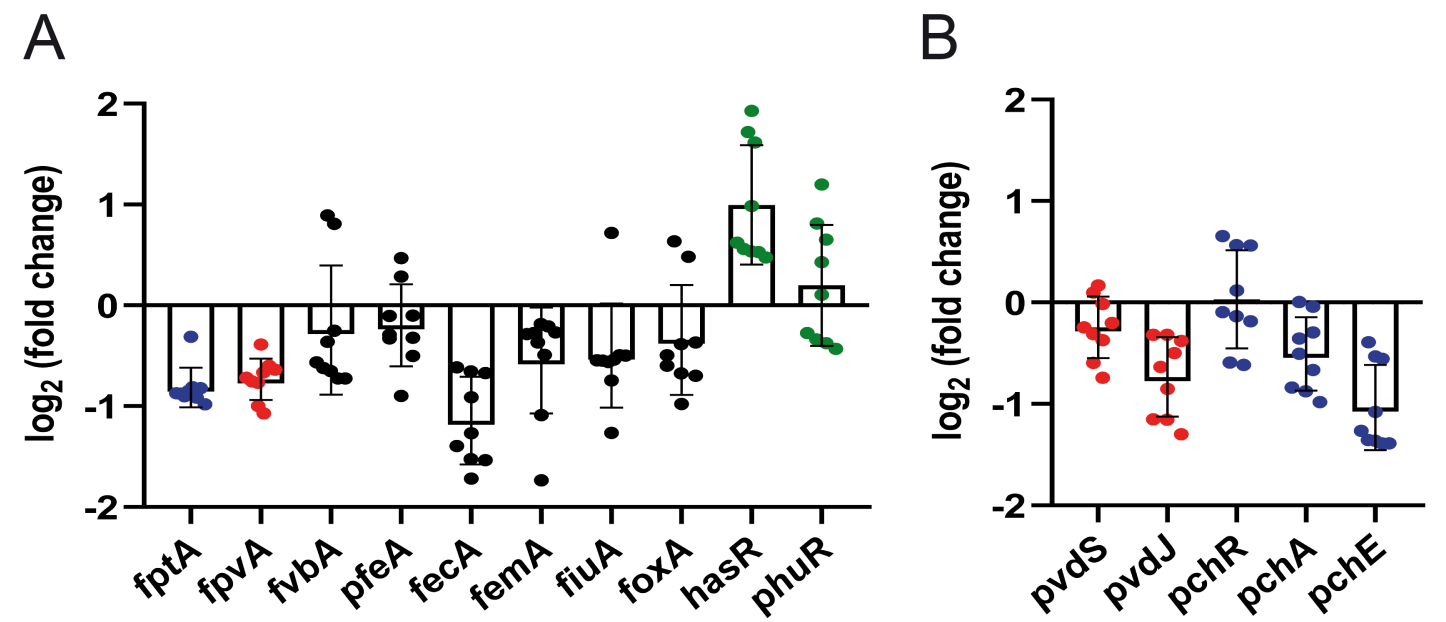

Figure 3. Modulation of the transcription of genes encoding outer membrane transporters involved in iron or hemin acquisition and genes of the PVD and PCH pathways in $P$. aeruginosa cells when grown in CAA medium with or without $0.25 \mu \mathrm{M}$ hemin. $P$. aeruginosa PAO1 was grown as for the proteomic analyses in CAA medium, with or without $0.25 \mu \mathrm{M}$ hemin, for $8 \mathrm{~h}$. Gene transcription was normalized to that of the housekeeping gene $u v r D$ reference gene. The results show the ratio between the values obtained in the presence of hemin over those obtained in the absence of hemin. A. fptA encodes the TBDT of PCH, fpvA that of PVD, $f v b A$ that of vibriobactin, $p f e A$ that of enterobactin, $f e c A$ that of citrate, $f e m A$ that of mycobactin and carboxymycobactin, fiuA that of ferrichrome, foxA that of DFOB and NOCA, and hasR and phuR that of hemin. B. $p v d J$ encodes an enzyme involved in PVD biosynthesis, $p c h A$ and $p c h E$ enzymes involved in PCH biosynthesis, $p v d S$ a sigma factor regulating the transcription of the PVD pathway and $p c h R$ a transcriptional regulator of the PCH pathway. The data show the mean of three independent experiments. The data concerning genes of the PVD pathway are shown in red in both graphs, those of the PCH pathway in blue, those of the hemin uptake pathways in green, and those encoding other outer membrane transporters in grey. 

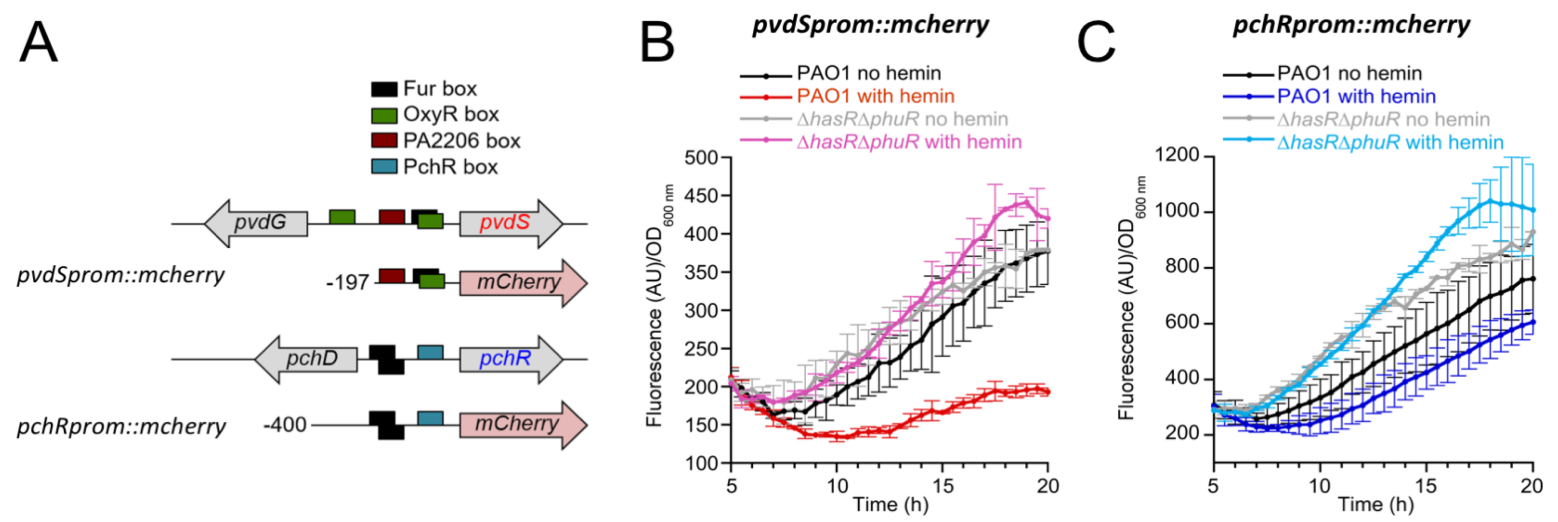

Figure 4. Expression of mCherry under the control of $p v d S$ or $p c h R$ promoters in $P$. aeruginosa PAO1 cells grown in CAA medium with or without $0.25 \mu \mathrm{M}$ hemin. A. Schematic representation of $p v d S$ and $p c h R$ promoters and plasmid constructs used in the experiments of panels A and B. Fur boxes are shown in black, OxyR boxes are shown in green, PA2206 boxes are shown in brown and the PchR boxes on the $p c h R$ promoter are shown in blue. B-C. P. aeruginosa PAO1 or $\Delta$ hasR $\Delta p h u R$ cells expressing mCherry under the control of the $p v d S$ promoter (plasmid: pvdSprom::mCherry) (panel B) or pchR promoter (plasmid: pchRprom::mCherry) (panel C) were grown overnight in CAA medium. Then, the cells were resuspended in CAA medium with or without $0.25 \mu \mathrm{M}$ hemin and the mCherry fluorescence monitored during bacterial growth. Curves represent the averages of three independent experiments. 
In terms of the other siderophore-dependent iron-uptake pathways present in the $P$. aeruginosa genome, RT-qPCR analysis showed very slight downregulation of the transcription of all the genes encoding xenosiderophore outer-membrane transporters tested, $f v b A, p f e A, f e c A, f e m A$, fiuA and foxA, but which may not be biologically significant (Figure 3). Finally, the proteomic data showed that the presence of $0.25 \mu \mathrm{M}$ hemin also slightly induced the expression of PA0434 and OprC in PAO1 (OprC is a TBDT involved in $\mathrm{Cu}$ uptake) (Figure 2).

In conclusion, the presence of $0.25 \mu \mathrm{M}$ hemin in the environment slightly represses the expression of the PVD and PCH-dependent iron-uptake pathways in P. aeruginosa, as well as the expression of several xenosiderophore-dependent iron-uptake pathways. This indicates that the bacteria adapt their phenotype to access iron, mostly via heme uptake, when heme is the major iron source present in their environment. This decrease in the expression of the various siderophore-dependent iron-uptake pathways could be due to two different regulating mechanisms. One possibility is that fewer PVD-, $\mathrm{PCH}$ and xenosiderophore-Fe complexes are formed and able to activate the expression of the corresponding iron-uptake pathways via transcriptional regulators. ${ }^{36,39,40}$ The second possibility is that the bacterial intracellular iron concentration increased, due to heme uptake, leading to repression of the transcription of the siderophore-dependent iron-uptake pathways via the Fur transcriptional regulator. When the intracellular iron concentration reaches a certain level, ferrous iron binds to Fur and the formed complex represses the transcription of iron-regulated genes, such as those encoding proteins involved in siderophore-dependent iron-uptake pathways. ${ }^{63}$ However, with such a scenario, one should also see a decrease in the expression of the proteins involved in heme import. We observed no repression in the expression of the heme-uptake pathway, because transcription of the genes involved is induced by the presence of hemin via the HasI and HasR transcriptional regulators, this positive regulation (activation of transcription) counteracting probably the negative regulation (repression of transcription) by Fur. 


\section{Repression of the expression of genes encoding proteins of the $\mathrm{PCH}$ - and PVD-dependent} iron-uptake pathways by hemin is HasR and PhuR dependent. We carried out differential proteomic analyses on the $\Delta h a s R \Delta p h u R$ mutant, deleted for both the has $R$ and $p h u R$ genes and consequently unable to import hemin into P. aeruginosa cells by the outer-membrane transporters HasR and PhuR (Figure 2 and Figure S1). We no longer observed the repression of the transcription and expression of the genes of the PCH-, PVD-, or xenosiderophoredependent iron-uptake pathways observed in PAO1 grown in the presence of hemin, in the $\Delta h a s R \Delta p h u R$ mutant. These data suggest that the repression of the expression of the genes encoding proteins of the PCH-, PVD- and xenosiderophore-dependent iron-uptake pathways by hemin requires the expression of has $R$ and $p h u R$ and the uptake of hemin by the bacteria and, consequently, involves Fur, the transcriptional regulator that senses the intracellular iron concentration.

\section{The presence of $0.25 \mu \mathrm{M}$ hemin downregulates the production of PVD and PCH. We} further investigated the effect of hemin on the expression of genes encoding proteins involved in the PVD- and PCH-dependent iron-uptake pathways by monitoring the amount of PVD and $\mathrm{PCH}$ produced by bacteria grown in the absence or presence of hemin. PAO1 was grown in CAA medium with or without $0.25 \mu \mathrm{M}$ hemin and aliquots removed at various times, the bacteria pelleted, and PVD and PCH concentrations monitored in the growth media (Figure 5). We observed an increase in PVD and $\mathrm{PCH}$ production for PAO1 grown in the absence of hemin after $8 \mathrm{~h}$ of culture, which reached a plateau after $16 \mathrm{~h}$ of approximately $290 \pm 35 \mu \mathrm{M} / \mathrm{OD}_{600 \mathrm{~nm}}$ for PVD and $92 \pm 37 \mu \mathrm{M} / \mathrm{OD}_{600 \mathrm{~nm}}$ for $\mathrm{PCH}$. The presence of hemin decreased PVD production by $49 \%\left(147 \pm 33 \mu \mathrm{M} / \mathrm{OD}_{600 \mathrm{~nm}}\right)$ and that of $\mathrm{PCH}$ by $48 \%\left(47 \pm 13 \mu \mathrm{M} / \mathrm{OD}_{600 \mathrm{~nm}}\right)$ after $24 \mathrm{~h}$ of culture (Figure 5). Such repression of PVD production was not observed in the $\Delta$ hasR $\Delta p h u R$ 
mutant and it was much less for PCH production. These data for PVD and PCH production are consistent with those for the transcription and expression of the PVD and PCH biosynthesis genes observed in the absence or presence of $0.25 \mu \mathrm{M}$ hemin in PAO1 and $\Delta h a s R \Delta p h u R$. Reduction in the expression of the enzymes involved in PVD and PCH biosynthesis in $P$. aeruginosa PAO1 cells grown in the presence of hemin resulted in the production of less siderophores. These data confirm that, in the presence of $0.25 \mu \mathrm{M}$ hemin, bacteria prefer to access iron by importing hemin than to use their own siderophores, PVD and $\mathrm{PCH}$, for ferric iron import. This is consistent with the work of Smith and Wilks showing a significant reduction of siderophore production by $P$. aeruginosa strains during the course of CF lung infection. ${ }^{50}$

The presence of $0.25 \mu \mathrm{M}$ hemin downregulates ${ }^{55} \mathrm{Fe}$ import by PVD and PCH. As described above, the presence of $0.25 \mu \mathrm{M}$ hemin slightly repressed the transcription and expression of the genes encoding outer-membrane transporters FpvA, FpvB, and FptA. We evaluated its impact on iron acquisition by the siderophores PVD and $\mathrm{PCH}$ by growing PAO1 in CAA minimal medium in the absence or presence of $0.25 \mu \mathrm{M}$ hemin for $16 \mathrm{~h}$. The cells were then used to monitor ${ }^{55} \mathrm{Fe}$ uptake via the siderophores PVD and $\mathrm{PCH}$. PAO1 was incubated in the presence of ${ }^{55} \mathrm{Fe}-\mathrm{PVD}$ or ${ }^{55} \mathrm{Fe}-\mathrm{PCH}$ complexes and aliquots removed at various times, the bacteria pelleted, and the radioactivity in the bacteria counted. In the absence of hemin in the growth culture, bacteria were able to acquire ${ }^{55} \mathrm{Fe}$ via $\mathrm{PVD}$ and $\mathrm{PCH}$, with uptake rates of $223 \pm 14$ $\mathrm{pmol} / \mathrm{ml} / \mathrm{OD}_{600} \mathrm{~nm}$ for PVD and $197.48 \pm 21.90 \mathrm{pmol} / \mathrm{ml} / \mathrm{OD}_{600} \mathrm{~nm}$ for PCH (Figure 6). When PAO1 was grown in the presence of $0.25 \mu \mathrm{M}$ hemin, less ${ }^{55} \mathrm{Fe}$ was taken up via PVD (162.18 $\pm 13.36 \mathrm{pmol} / \mathrm{ml} / \mathrm{OD}_{600} \mathrm{~nm}$ after $\left.3 \mathrm{~h}\right)$ and $\mathrm{PCH}\left(160.00 \pm 22.39 \mathrm{pmol} / \mathrm{ml} / \mathrm{OD}_{600 \mathrm{~nm}}\right.$ after $\left.3 \mathrm{~h}\right)$ (Figure 6A). Carbonyl cyanide-m-chlorophenylhydrazone (CCCP), an inhibitor of the innermembrane proton motive force, was used to verify that the ${ }^{55} \mathrm{Fe}$ uptake observed was not a consequence of iron diffusion across the bacterial membranes but due to the active uptake via 
TBDTs. Indeed, CCCP inhibits all proton motive-dependent uptake in Gram-negative bacteria, such as the uptake of iron via siderophores. ${ }^{66}$ In the presence of CCCP, no ${ }^{55} \mathrm{Fe}$ uptake by PVD or PCH was observed in the absence or presence of hemin in the bacterial culture (Figure 6), indicating that the uptake observed occurred via TBDTs and was not due to diffusion across porins.
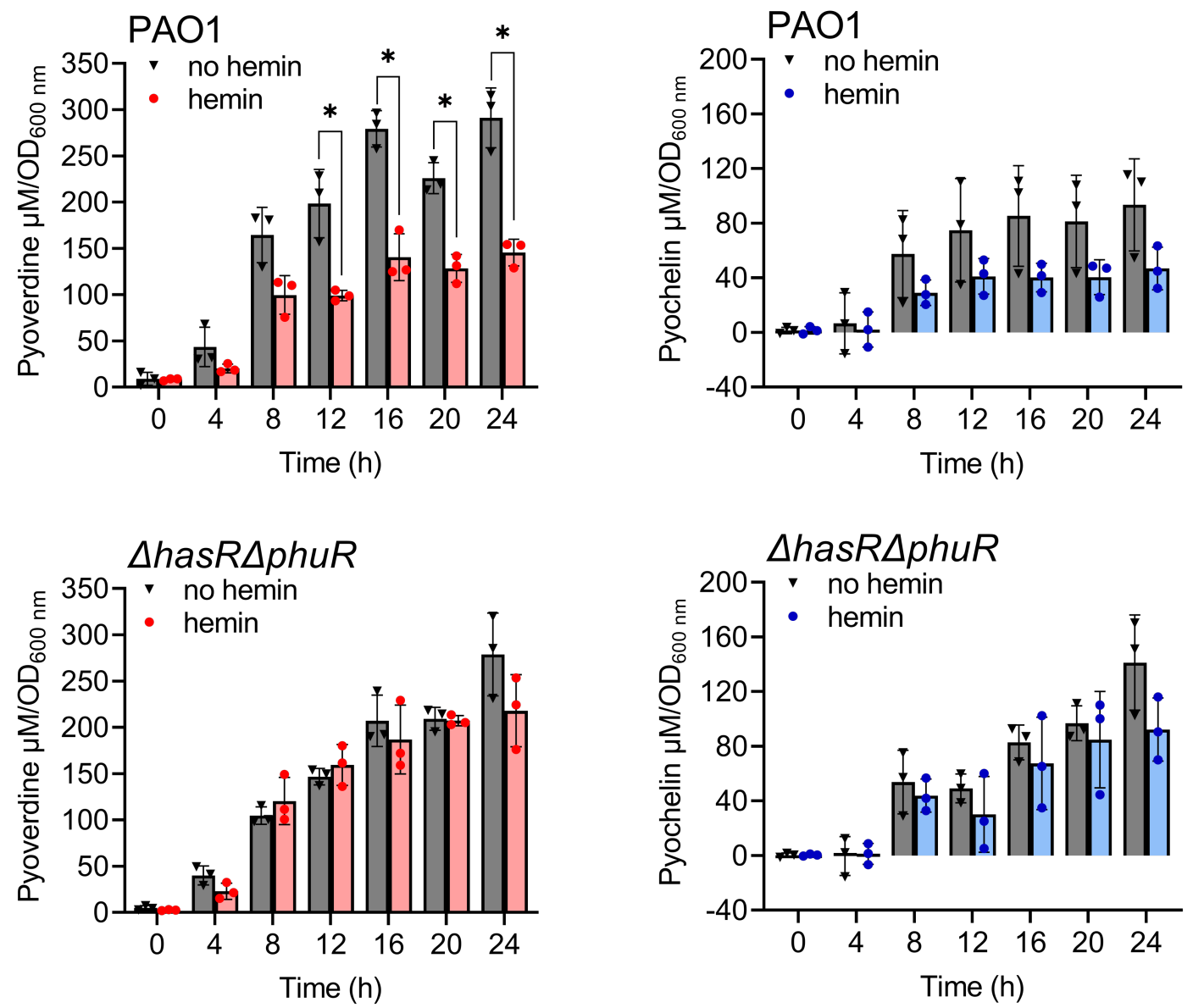

Figure 5. PVD and PCH production by $P$. aeruginosa $\mathrm{PAO1}$ in the absence or presence of $\mathbf{0 . 2 5} \boldsymbol{\mu M}$ hemin. Bacteria were grown in CAA medium with or without $0.25 \mu \mathrm{M}$ hemin. PVD (A) and $\mathrm{PCH}(\mathbf{B})$ production $\left(\mu \mathrm{M} / \mathrm{OD}_{600} \mathrm{~nm}\right)$ was monitored during bacterial growth as described in materials and methods. The histogram values represent the averages of three independent experiments. The indicated $\mathrm{p}$ values as determinated by a Student's $t$ test $(* \mathrm{p}<0.05)$. 

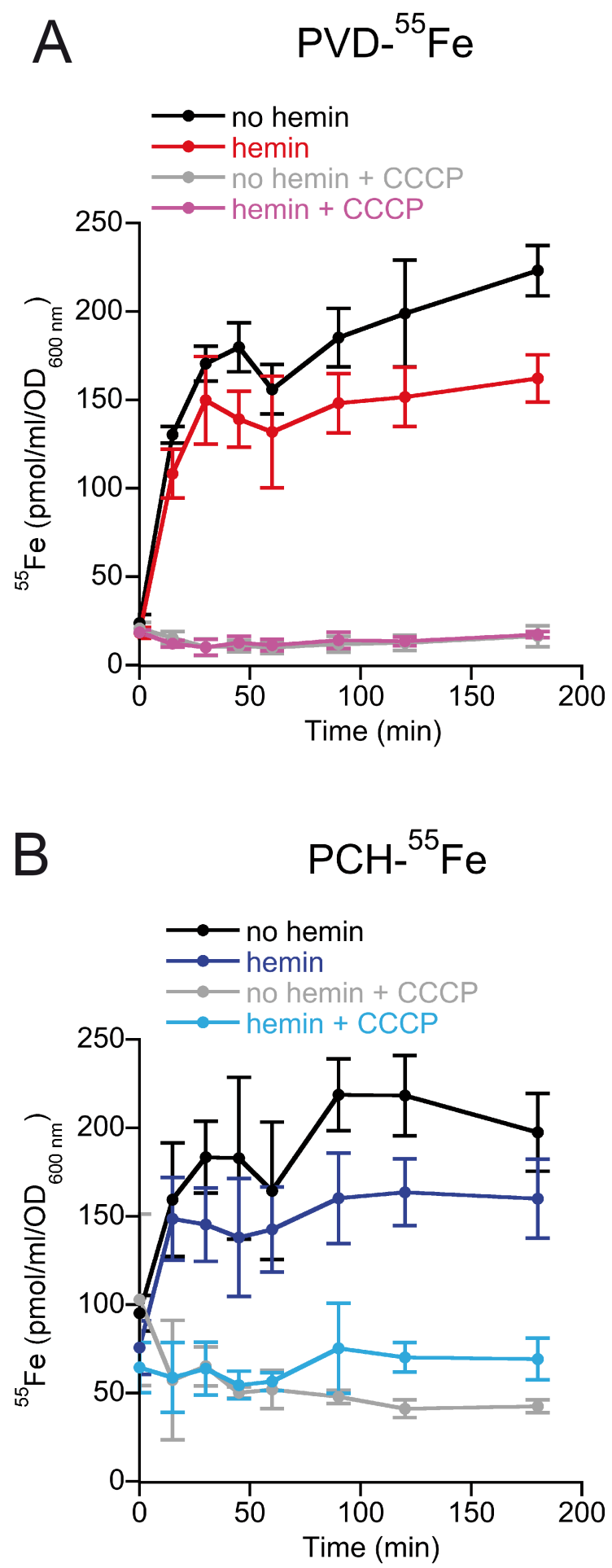

Figure 6. Kinetics of ${ }^{55} \mathrm{Fe}$ uptake via $\mathrm{PVD}$ or $\mathrm{PCH}$ in $P$. aeruginosa $\mathrm{PAO1}$ cells grown in the absence or presence of $0.25 \boldsymbol{\mu M}$ hemin. The PAO1 strain was grown in CAA medium with or without hemin $(0.25 \mu \mathrm{M})$ for $16 \mathrm{~h}$. Then, bacterial cells were washed in $50 \mathrm{mM}$ Tris$\mathrm{HCl} \mathrm{pH} 8.0$ and resuspended in the same buffer. Transport assays were initiated by adding 500 $\mathrm{nM}{ }^{55} \mathrm{Fe}-\mathrm{PVD}(\mathbf{A})$ or ${ }^{55} \mathrm{Fe}-\mathrm{PCH}$ (B). Aliquots were removed at various times, centrifuged, and the radioactivity in the bacterial pellet measured. Results are expressed as atoms of ${ }^{55} \mathrm{Fe}$ transported per cell. Bacteria were also treated with $200 \mu \mathrm{M}$ of the protonophore CCCP to inhibit active iron uptake and visualize any iron diffusion across the bacterial membrane. 
In conclusion, the presence of hemin in the bacterial growth medium induces the partial repression of ${ }^{55} \mathrm{Fe}$ uptake into $P$. aeruginosa cells by $\mathrm{PVD}$ and $\mathrm{PCH}$ due to the downregulation of $f p v A, f p v B$, and $f p t A$ transcription and expression of the corresponding transporters. Overall, the data presented above show that the growth of $P$. aeruginosa cells in CAA medium in the presence of $0.25 \mu \mathrm{M}$ hemin results in expression of the Has and Phu pathways and strong repression of the PVD and PCH pathways (Table S1), but in a way that does not completely abolish production of these two siderophores and iron uptake via these PVD- and PCHdependent pathways. It is likely that bacteria use both strategies to access iron in CAA medium supplemented with $0.25 \mu \mathrm{M}$ hemin, mainly hemin uptake and at a lesser extend ferric iron uptake by PVD and PCH. If hemin becomes rare, the bacteria can easily and quickly switch to iron access solely through their siderophores.

\section{Adaptation of the expression of the genes involved in the various iron-uptake pathways of} P. aeruginosa PAO1 to the presence of hemin and xenosiderophores. We explored the effects of a mixture of $0.25 \mu \mathrm{M}$ hemin and $10 \mu \mathrm{M} \mathrm{TCV}$, a synthetic catechol synthetic siderophore (Figure S3), and $0.25 \mu \mathrm{M}$ hemin and $10 \mu \mathrm{M}$ nocardamine (NOCA), a hydroxamate siderophore (Figure S3), on P. aeruginosa PAO1 by differential proteomics. TCV is a synthetic analogue of the E. coli-produced siderophore enterobactin and is used in the literature for antibiotic vectorization. ${ }^{45}$ Previous studies have shown that the presence of TCV or TCVantibiotic compounds in the bacterial environment induces the transcription and consequently the expression of the TBDT $p f e A$, which is the ferri-enterobactin outer-membrane transporter, and $p f e E$, the esterase that hydrolyzes enterobactin to release bound iron. ${ }^{26}$ Iron-loaded TCV or TCV-antibiotic is imported, like ferri-ENT, by PfeA across the outer membrane. ${ }^{45,67}$ NOCA induces the transcription of fox $A$ gene, FoxA being the TBDT internalizing the ferric form of NOCA..$^{35}$ 
As previously described, our differential proteomic data showed that the presence of $10 \mu \mathrm{M}$ TCV alone in the medium of PAO1 induces the expression of $p f e A\left(\log _{2}\right.$ fold change of 4.81), $p f e E$ ( $\log _{2}$ fold change of 5.55), and pirA, another TBDT also involved in iron uptake via catechol xenosiderophores, $\left(\log _{2}\right.$ fold change of 2.05). ${ }^{26,41,45,67,68}$ The presence of TCV also resulted in the repression of $f p t A$ expression ( $\log _{2}$ fold change of -2.37) and that of many genes encoding proteins of the $\mathrm{PCH}-d e p e n d e n t$ iron-uptake pathway (Figure 7A). In the presence of both $10 \mu \mathrm{M}$ TCV and $0.25 \mu \mathrm{M}$ hemin, the expression of $p f e A$ and pirA was still induced with the same efficiency as with TCV alone. In addition, the expression of the various genes encoding proteins of the PCH pathway and $f v b A$ (the TBDT of the catechol siderophore vibriobactin) were more highly repressed than in the presence of TCV alone. Taken together, these observations clearly show an additive effect of the $0.25 \mu \mathrm{M}$ hemin with the presence of $10 \mu \mathrm{M}$ TCV (Figure 7B). In addition, we also observed slight repression of the expression of the outer-membrane transporter $f p v A$ and no significant effect on the expression of the various other genes encoding proteins of the PVD pathway. By contrast, has $R$ expression increased slightly ( $\log _{2}$ fold change of 0.63 ; Figure $7 C$ ). No effect was observed on the expression of the genes encoding other proteins of the Has pathway or those of the Phu and Hxu pathways. RTqPCR was used to confirm the proteomic data for $p f e A$, hasR, fpvA and fptA (Figure 8) and equivalent data were obtained. We also obtained similar results when $P$. aeruginosa was grown in the presence of $10 \mu \mathrm{M}$ enterobactin (ENT) or a mixture of $0.25 \mu \mathrm{M}$ hemin and $10 \mu \mathrm{M}$ ENT (Figure S4).

In the presence of $10 \mu \mathrm{M}$ NOCA alone, fox $A$ expression was induced, as previously described ( $\log _{2}$ fold change of 8.43 ; Figure $\left.9 \mathrm{~A}\right) .{ }^{35}$ In parallel, we observed downregulation of the expression of the $\mathrm{PCH}$ transporter fptA and other proteins of this pathway. Growth of the bacteria in the presence of $10 \mu \mathrm{M}$ NOCA and $0.25 \mu \mathrm{M}$ hemin (Figure 9) still resulted in an increase in the expression of fox $A$ gene with, in addition, a small induction of hasR expression 
( $\log _{2}$ fold change of 0.75$)$. On the contrary, we observed stronger repression of $f p t A$ expression and that of various genes encoding proteins of the PCH pathway than with NOCA alone, as well as slight repression of the expression of $f p v A$ and $f p v B$, the two TBDTs of the PVD pathway. These results were confirmed by RT-qPCR (Figure 8) and equivalent data were obtained when $P$. aeruginosa was grown in the presence of $10 \mu \mathrm{M}$ DFOB and $0.25 \mu \mathrm{M}$ hemin (Figure S5). The expression of all other genes encoding proteins of the PVD pathway (except for $\operatorname{opmQ)}$ ) was less strongly affected by the presence of both hemin and NOCA. 

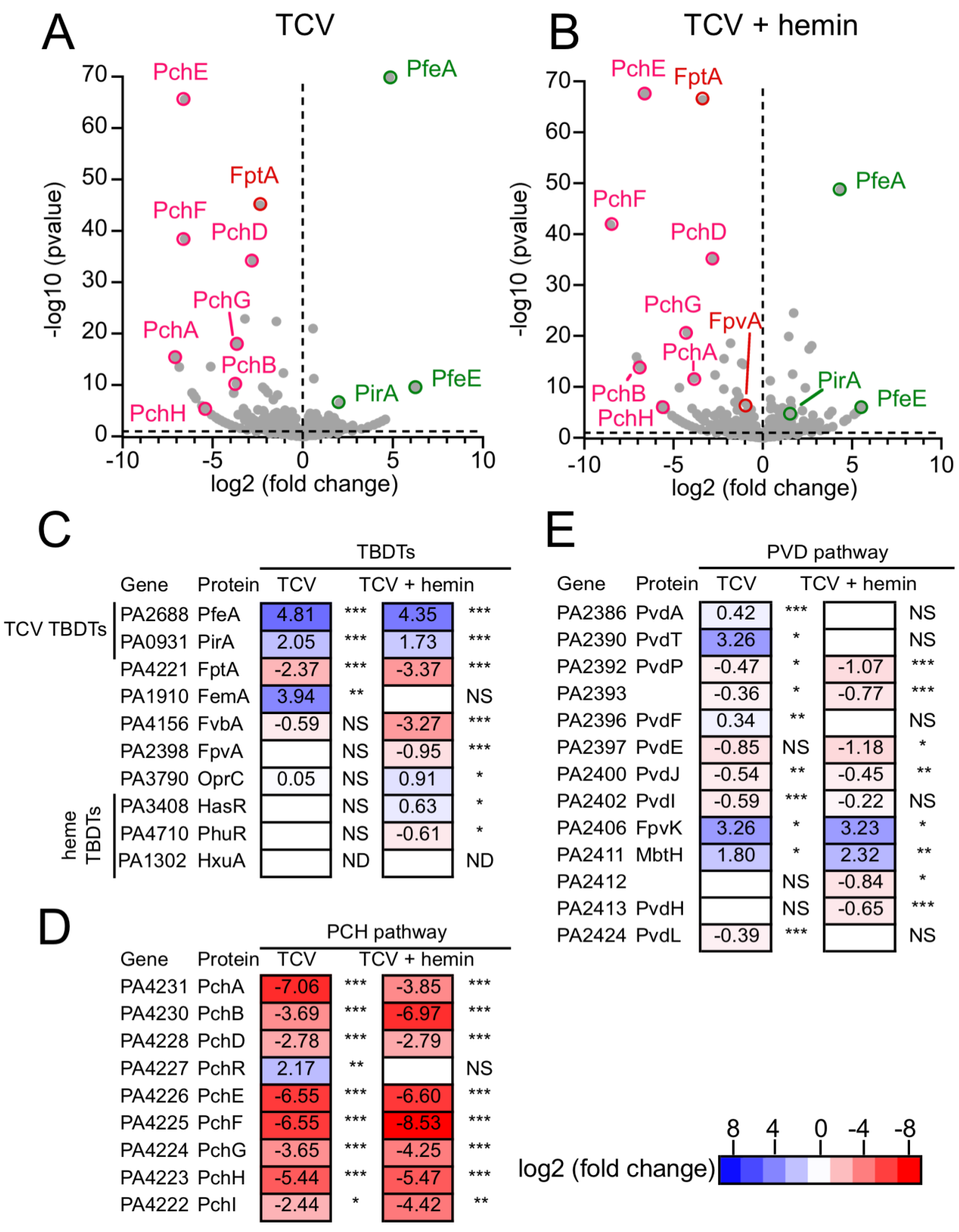

Figure 7. Differential proteomic analyses of $P$. aeruginosa PAO1 grown in the absence or presence of TCV or TCV and hemin. A. PAO1 cells were grown in CAA medium with or without $10 \mu \mathrm{M}$ TCV for $8 \mathrm{~h}$. The average values measured in CAA without TCV were plotted against the average values in CAA supplemented with NOCA. B. The same experiment was repeated with PAO1 cells grown in CAA with or without $10 \mu \mathrm{M} \mathrm{TCV}$ and $0.25 \mu \mathrm{M}$ hemin. $\mathbf{C}-$ E. Heat maps of various TBDTs $(\mathbf{C})$ or proteins involved in the PCH (D) or PVD pathways (E). In these heat maps, we chose to show HasR, PhuR and HxuA and the proteins for which a change in the level of expression was observed in one of the two conditions analyzed (TCV or $\mathrm{TCV}+$ hemin). The darker the shade of blue, the more expression of the protein is induced; the darker the shade of red, the more expression of the protein is repressed. NS: data not significant; ND: not detected (no peptide corresponding to the protein was detected by proteomic); ${ }^{*} \mathrm{p}<$ $0.05, * * \mathrm{p}<0.01$, and $* * * \mathrm{p}<0.001$ 

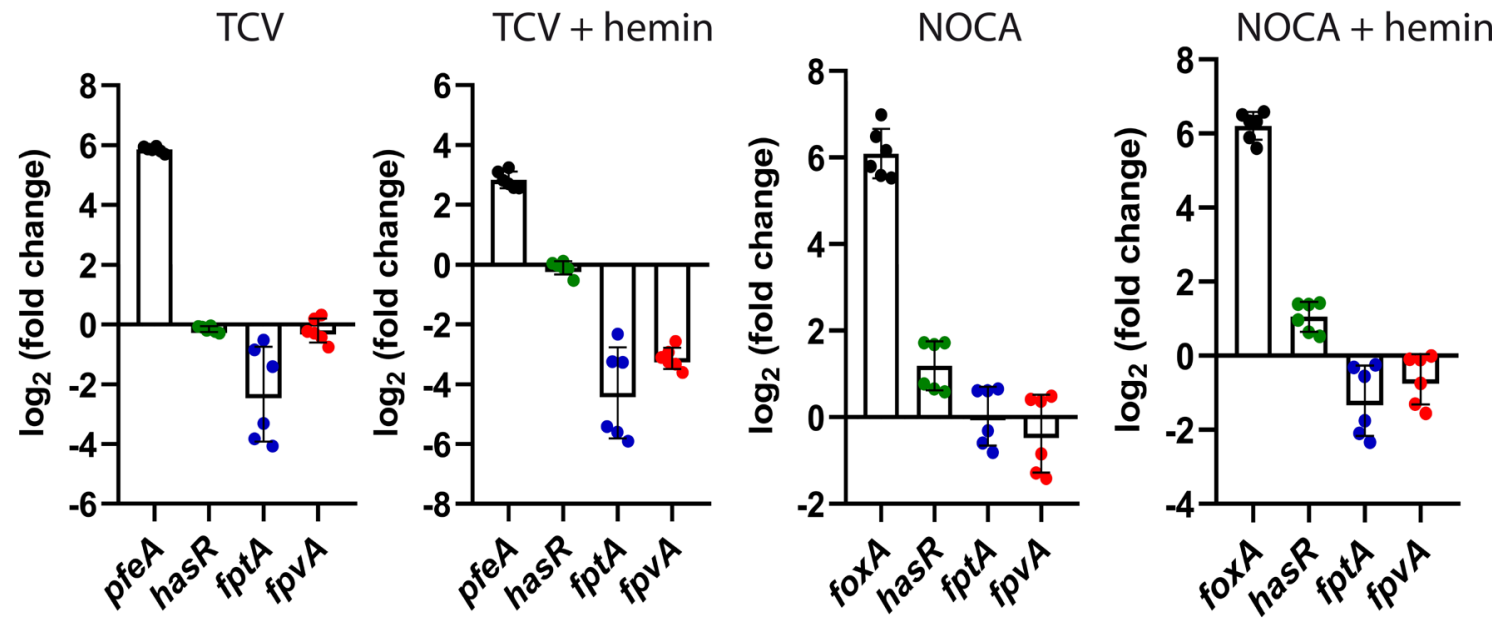

Figure 8. Modulation of the transcription of $p f e A, f o x A$, hasR, $f p t A$, and $f p v A$ in the absence or presence of TCV, TCV with hemin, NOCA, or NOCA with hemin. $P$. aeruginosa PAO1 was grown in the presence of $10 \mu \mathrm{M} \mathrm{TCV}, 10 \mu \mathrm{M} \mathrm{TCV}$ with $0.25 \mu \mathrm{M}$ hemin, $10 \mu \mathrm{M}$ NOCA, or $10 \mu \mathrm{M}$ NOCA with $0.25 \mu \mathrm{M}$ hemin for $8 \mathrm{~h}$. Gene transcription was normalized to that of the housekeeping $u v r D$ reference gene. The results show the ratio between the values obtained in the presence of TCV, TCV with hemin, NOCA, or NOCA with hemin and those obtained in CAA. fptA encodes the TBDT of PCH, fpvA that of PVD, pfeA that of enterobactin, foxA that of NOCA and DFO-B, and hasR that of heme. The data show the mean of six independent experiments.

In summary, these results show that, in the presence of a mixture of hemin and a xenosiderophore, the xenosiderophore activates the expression of the gene encoding its corresponding TBDT. In addition, the expression of the genes of the $\mathrm{PCH}$ pathway is more strongly repressed than in the presence of only hemin or only a xenosiderophore, indicating that both iron sources (hemin or xenosiderophore having scavenged iron) have a cumulative effect in the phenotypic adaptation of $P$. aeruginosa concerning the expression of its various ironuptake pathways. Such phenotypic adaptation of $P$. aeruginosa in the presence of hemin and a xenosiderophore indicates that the pathogen is able to access both hemin and ferric iron in such an environment. In this context, ferric iron uptake occurs via the xenosiderophore present rather than by PVD and PCH. This is a key point for the vectorization of antibiotics by siderophores. ${ }^{43-}$ ${ }^{45}$ Such high phenotypic plasticity concerning the various iron-uptake pathways present in the 
$P$. aeruginosa genome is an asset in the development of siderophore-antibiotic conjugates and the use of these uptake pathways to transport antibiotics into bacteria.

In the context of infection, $P$. aeruginosa grows under iron-restricted conditions and is also in the presence of heme, which is mostly bound to hemoproteins, such as hemoglobin and myoglobin. In such a context, based on the data presented here, the Has and Phu uptake pathways are highly expressed, PVD- and PCH-dependent iron-uptake pathways are also expressed but at a lower level compared to iron-restricted growth conditions in the absence of heme. This is consistent with previous data showing that heme is a critical source of iron during prolonged infection of the CF lung and that $P$. aeruginosa strains produce significantly less siderophores during the course of CF lung infection. ${ }^{16,48-52}$ In such an infection context, according to the present data, if a catechol- or hydroxamate-type xenosiderophore is present or a siderophore-antibiotic conjugate, its corresponding uptake pathway is certainly expressed, despite the presence of heme. We previously showed that the presence of TCV-linezolide induces the expression of the corresponding uptake pathway in $P$. aeruginosa in an infection model (infection of epithelial cells). ${ }^{45}$ 

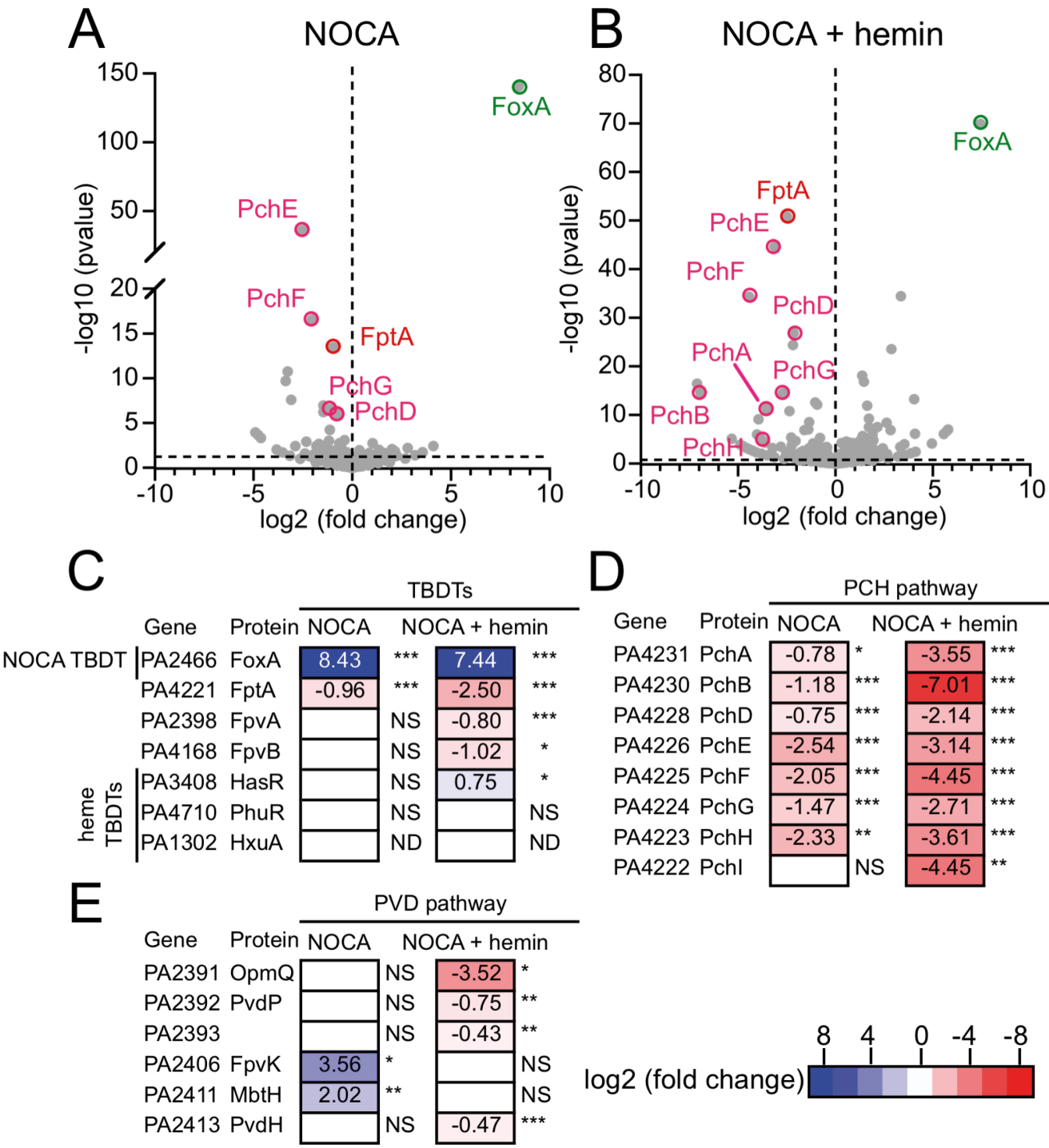

D Gene Protein NOCA NOCA + hemin PA4231 PchA -0.78 * -3.55 *** PA4230 PchB PA4228 PchD PA4226 PchE PA4225 PchF PA4224 PchG PA4223 PchH PA4222 Pchl

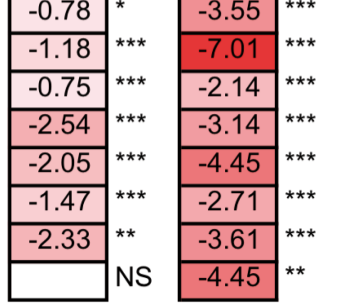

Figure 9. Differential proteomic analyses of $P$. aeruginosa PAO1 grown in the absence or presence of NOCA or NOCA with hemin. A. PAO1 cells were grown in CAA medium with or without $10 \mu \mathrm{M}$ NOCA for $8 \mathrm{~h}$. The average values measured in CAA without NOCA were plotted against the average values in CAA supplemented with NOCA. B. The same experiment was repeated with PAO1 cells grown in CAA with or without $10 \mu \mathrm{M}$ NOCA and $0.25 \mu \mathrm{M}$ hemin. C-E. Heat maps of various TBDTs $(\mathbf{C})$ or proteins involved in the PCH (D) or PVD pathways (E). In these heat maps, we chose to show HasR, PhuR and HxuA for the TBDTs and the transporters or proteins for which a change in the level of expression was observed in one of the two conditions analyzed (NOCA or NOCA + hemin). The darker the shade of blue, the more expression of the protein is induced; the darker the shade of red, the more expression of the protein is repressed. NS: data not significant; ND: not detected (no peptide corresponding to the protein was detected by proteomic); ${ }^{*} \mathrm{p}<0.05, * * \mathrm{p}<0.01$, and $* * * \mathrm{p}<0.001$ 


\section{CONCLUSION}

As described in the introduction and summarized in Table $\mathrm{S} 1$, the genome of $P$. aeruginosa includes genes encoding at least 15 different iron or heme-uptake pathways. ${ }^{69}$ They are not all expressed simultaneously and the bacteria do not express just one iron-uptake pathway at a time, but usually a combination of a few, those with the highest chance to scavenge iron or hemin from the growth environment. ${ }^{26,35,41,45}$ Consequently, as we already discussed previously "the presence of a large panel of iron-acquisition pathways in the genome involves an even larger panel of possible phenotypes, with various combinations of expression of these ironuptake pathways and with various expression levels, depending on the environmental stimuli". ${ }^{26}$ Data we previously obtained, using the same differential proteomic approach as used here, showed that the growth of $P$. aeruginosa in CAA versus LB resulted in the induction of the expression of the PVD- and PCH-dependent iron-uptake pathways, as well as the hemeuptake pathways Has and Phu, chtA, encoding the TBDT of the siderophores aerobactin, rhizobactin and schizobactin, ${ }^{37}$ pirA, a gene encoding a ferri-catechol siderophore TBDT, two TBDTs for which the siderophore transported is still unknown, PA0434 and PA3268, and oprC, a TBDT involved in $\mathrm{Cu}$ uptake ${ }^{54}$ (Table $\mathrm{S} 1$ ). The presence of $0.25 \mu \mathrm{M}$ hemin in CAA growth medium slightly increased the expression of $h a s R$ and $p h u R$ and downregulated the expression of the genes encoding the proteins of the PVD- and PCH-dependent iron-uptake pathways, resulting in less production of PVD and PCH. However, efficient iron uptake via PVD and PCH was still possible in cells grown in CAA in the presence of hemin. Consequently, bacteria grown in CAA in the presence of hemin can both import hemin and access ferric iron via their siderophores PVD and PCH. In the simultaneous presence of hemin and a xenosiderophore, such as NOCA, DFOB, ENT, or the synthetic catechol chelator TCV, strong induction of the expression of the corresponding xenosiderophore-uptake pathways occurred, as well as repression of the PVD- and PCH-dependent iron-uptake pathways. Such expression of the 
xenosiderophore iron-uptake pathway is an asset for the vectorization of antibiotics by siderophores, as discussed above. Indeed, during an infection, even if heme is present in the environment of the pathogen, the bacteria will upregulate the expression of the uptake pathways of the siderophore-antibiotic conjugates if such compounds are present in their environment. Overall, these data provide precise insights on how $P$. aeruginosa adjusts the expression of its various iron-uptake pathways to match the presence of hemin and hemin with a xenosiderophore. These phenotypic patterns (described in Table S1) show amazing plasticity and can be finely modulated and adjusted by environmental stimuli, such as the presence of hemin or xenosiderophores.

\section{METHODS}

Chemicals. Hemin chloride (hemin), desferrioxamine B (DFOB) and the protonophore carbonyl cyanide m-chlorophenylhydrazone (CCCP) were purchased from Sigma-Aldrich and ${ }^{55} \mathrm{FeCl}_{3}$ was purchased from Perkin Elmer. NOCA was purified as described. ${ }^{70}$ Pyoverdine (PVD) was purified from $P$. aeruginosa PAO1 culture supernatants as previously described..$^{71}$ Pyochelin $(\mathrm{PCH})$ was synthetized as previously described ${ }^{72}$ as well as TCV. ${ }^{67}$

Hemin preparation. A stock solution of hemin $(1 \mathrm{mM})$ was prepared by dissolution in $\mathrm{NaOH}$ (0.1 M). Following filtration, the solution was diluted (1:1,000), and hemin concentration was determined at $385 \mathrm{~nm}$ using an extinction coefficient of $58,4001 \cdot \mathrm{mol}^{-1} \cdot \mathrm{cm}^{-1}$.

Bacterial strains and growth conditions. Strain used are summarized in Table S2. Bacteria were first grown in LB medium overnight at $30^{\circ} \mathrm{C}$. Cells were then washed and resuspended in iron-deficient CAA (casamino acid) medium containing $5 \mathrm{~g} \mathrm{l}^{-1}$ low-iron CAA (Difco), $1.46 \mathrm{~g} \mathrm{l}^{-}$ 
${ }^{1} \mathrm{~K}_{2} \mathrm{HPO}_{4} 3 \mathrm{H}_{2} \mathrm{O}$ and $0.25 \mathrm{~g} \mathrm{l}^{-1} \mathrm{MgSO}_{4} 7 \mathrm{H}_{2} \mathrm{O}$ and were grown overnight at $30^{\circ} \mathrm{C}$. To monitor growth in the presence of siderophores, cells were resuspended again in fresh CAA medium at an optical density of $\mathrm{OD}_{600 \mathrm{~nm}}=0.01$ or 0.1 with or without $0.25 \mu \mathrm{M}$ hemin in 96 well plates. Plates were incubated at $30^{\circ} \mathrm{C}$, with shaking every $15 \mathrm{~min}$, in a microplate reader (Infinite M200, Tecan). Growth was followed by measuring the optical density at $600 \mathrm{~nm}$ every $30 \mathrm{~min}$, for $20 \mathrm{~h}$.

Construction of hasR and phuR mutants. Enzymes were obtained from ThermoFisher Scientific. Escherichia coli TOP10 (Invitrogen) was used as the host strain for the plasmids. Plasmid construction and primers (Table S4) were used as described previously. ${ }^{68}$ Briefly, 1,400-bp inserts made up of the flanking sequences of either has $R$ or phuR were cloned into a pEXG2 plasmid using HindIII and EcoRI restriction sites for hasR and phuR. Plasmids were sequenced before being used to generate chromosomal mutations in a $P$. aeruginosa PAO1 strain as previously described. ${ }^{68}$ Recombinant clones were isolated before being verified by PCR and Sanger sequencing.

Construction of mCherry reporter plasmids and mCherry expression monitoring. Enzymes were obtained from ThermoFisher Scientific. Escherichia coli SM10 (Invitrogen) was used as the host strain for the plasmids. DNA fragments containing $197 \mathrm{bp}$ of the $p v d S$ promoter before the ATG and $400 \mathrm{bp}$ of the $p c h R$ promoter before the ATG were amplified by PCR. Sequence encoding for mCherry was amplified by PCR using primers containing flanking region of $p v d S$ or $p c h R$ promoter (Table S4). A second PCR was used to generate a 908 bp fragment containing the $p v d S$ promoter or a $1111 \mathrm{bp}$ fragment containing the $p c h R$ promoter in frame with mCherry coding sequence. Each PCR product was purified, digested with BamHI and EcoRI for $p v d S$ - 
mCherry or with HindIII and EcoRI for $p c h R$-mCherry, and then introduced into pSEVA631 vector. Recombinant clones were isolated before being verified by PCR and Sanger sequencing. Bacterial growth and mCherry expression were followed by measuring the optical density at $600 \mathrm{~nm}$ and fluorescence at $610 \mathrm{~nm}$ (excitation at $570 \mathrm{~nm}$ ), every $30 \mathrm{~min}$, for $20 \mathrm{~h}$. The mean of three independent replicates were represented for each measurement.

RNA extractions. $P$. aeruginosa PAO1 cells were consecutively grown overnight in LB and then in CAA medium. Afterwards, bacteria were pelleted and diluted again in CAA medium at an $\mathrm{OD}_{600 \mathrm{~nm}}$ of 0.1 and grown for $8 \mathrm{~h}$ with or without $0.25 \mu \mathrm{M}$ hemin and/or $10 \mu \mathrm{M}$ siderophore (NOCA or TCV) at $30^{\circ} \mathrm{C}$. Afterwards, $2.5 \times 10^{8}$ cells were mixed with two volumes of RNAprotect Bacteria Reagent (Qiagen). Samples were lysed in Tris-EDTA pH 8.0 containing $15 \mathrm{mg} / \mathrm{ml}$ lysozyme (Sigma-Aldrich) for 15 minutes at $25^{\circ} \mathrm{C}$. Then, lysates were homogenized with QIAshredder kit (Quiagen) and total RNAs were extracted with RNeasy mini kit (Quiagen). After treatment with DNase (RNase-Free DNase Set, Qiagen), RNAs were purified with an RNeasy Mini Elute cleanup kit (Qiagen).

RT-qPCR analysis. $1 \mu \mathrm{g}$ of RNA was reversed-transcribed with a High Capacity RNA to cDNA Kit, in accordance with the manufacturer's instructions (Applied Biosystems). The expression of genes was measured in a SpetOne Plus Instrument (Applied Biosystems), with Power Sybr Green PCR Master Mix (Applied Biosystems) and the appropriate primers (listed in Table S5). The $u v r D$ expression was used as an internal control. For a given gene in each strain, the transcript levels were normalized with respect to those for $u v r D$ and were expressed as a base two logarithms of the ratio (fold-change) relative to the reference conditions. 
Iron uptake. Complexes of siderophore- ${ }^{55} \mathrm{Fe}$ were prepared like previously described ${ }^{73}$ in 50 $\mathrm{mM}$ Tris- $\mathrm{HCl} \mathrm{pH} 8.0$ buffer and with a siderophore:iron ratio of 20:1. P. aeruginosa PAO1 cells were consecutively grown overnight in LB and then in CAA medium. Afterwards, bacteria were pelleted and diluted again in CAA medium at an $\mathrm{OD}_{600 \mathrm{~nm}}$ of 0.1 and grown overnight with or without $0.25 \mu \mathrm{M}$ hemin. After growth, bacteria were pellet, washed with $50 \mathrm{mM}$ Tris$\mathrm{HCl} \mathrm{pH} 8.0$, and diluted to an $\mathrm{OD}_{600} \mathrm{~nm}$ of 1.0. Half of the cells were incubated during 15 minutes with $200 \mu \mathrm{M} \mathrm{CCCP}$ at $30^{\circ} \mathrm{C}$. Both samples of bacteria (treated or not with CCCP) were incubated with $500 \mathrm{nM}$ siderophore- ${ }^{55} \mathrm{Fe}$. At 0, 15, 30, 45, 60, 120 and 180 minutes, aliquots were removed, cells were harvested and radioactivity measured in the bacterial pellets.

PVD and PCH measurement. The production of PCH and PVD were measured as described previously. ${ }^{74} \mathrm{PVD}$ and $\mathrm{PCH}$ production were monitored using their characteristic absorbance at $400 \mathrm{~nm}$ (at neutral $\mathrm{pH}$ ) and $320 \mathrm{~nm}$ respectively. Bacteria were centrifuged and PVD absorbance at $400 \mathrm{~nm}$ was directly measured in the supernatant. PCH was extracted from the supernatant with ethyl-acetate. $500 \mu 1$ ethyl-acetate was added to $1 \mathrm{ml}$ of bacterial supernatant acidified by solid citric acid until a $\mathrm{pH}$ 3.0, mixed and centrifuged to separate aqueous and organic phases. The concentration of $\mathrm{PCH}$ was determinate by measuring the absorbance at 320 $\mathrm{nm}$ in the organic phase.

Proteomic analysis. P. aeruginosa PAO1 cells were consecutively grown overnight in LB and then in CAA medium. Afterwards, bacteria were pelleted and diluted again in CAA medium at an $\mathrm{OD}_{600 \mathrm{~nm}}$ of 0.1 and grown for $8 \mathrm{~h}$ with or without $0.25 \mu \mathrm{M}$ hemin and/or $10 \mu \mathrm{M}$ siderophore (NOCA or TCV) at $30^{\circ} \mathrm{C}$. The cells $\left(5 \times 10^{8}\right)$ were harvested and used for proteomic analysis. Each sample was prepared in biological triplicate for each cell-culture condition. Cell pellets 
were resuspended in $200 \mu \mathrm{L}$ lysis buffer (UTCT buffer containing $7 \mathrm{M}$ urea, $2 \mathrm{M}$ thiourea, 4\% CHAPS, and $20 \mathrm{mM}$ Tris- $\mathrm{HCl} \mathrm{pH}$ 7.6) supplemented with nuclease and DNase. Protein concentrations were determined with the Bradford assay using bovine serum albumin as the standard. Proteins were further precipitated overnight with glacial $0.1 \mathrm{M}$ ammonium acetate in $100 \%$ methanol ( 5 volumes, $-20^{\circ} \mathrm{C}$ ). After centrifugation at $12,000 \mathrm{x}$ g and $4^{\circ} \mathrm{C}$ for $15 \mathrm{~min}$, the resulting pellets were washed twice with $0.1 \mathrm{M}$ ammonium acetate in $80 \%$ methanol and further dried under vacuum (Speed-Vac concentrator). Pellets were resuspended in $100 \mu \mathrm{L} 50 \mathrm{mM}$ ammonium bicarbonate and submitted to reduction $\left(5 \mathrm{mM}\right.$ dithiothreitol, $\left.95^{\circ} \mathrm{C}, 10 \mathrm{~min}\right)$ and alkylation (10 mM iodoacetamide, room temperature, $20 \mathrm{~min})$. Proteins were finally digested overnight with $150 \mathrm{ng}$ sequencing-grade trypsin (Promega). The proteomic datasets were obtained by injecting $750 \mathrm{ng}$ of each peptide mixture into a Q-Exactive Plus mass spectrometer coupled to an EASY-nanoLC-1000 (Thermo-Fisher Scientific, USA) as described previously 26. The raw data obtained were converted into .mgf files using Proteome Discoverer Daemon software (Thermo-Fisher Scientific, script “Export-to-mgf”, version 2.2). For both differential proteomic analyses, data were searched against the $P$. aeruginosa UniprotKB sub-database (UniprotKB release 2016_12, taxon 208964, P. aeruginosa strain PAO1, 5564 forward protein sequences). Peptides and proteins were identified using the Mascot algorithm (version 2.5.1, Matrix Science, London, UK). The following parameters were used: (i) Trypsin/P was selected as the enzyme, (ii) two missed cleavages were allowed, (iii) methionine oxidation and acetylation of protein $\mathrm{N}$-term were set as variable modifications and carbamidomethylation of cysteine as a fixed modification, (iv) mass tolerance for precursor ions was set at $10 \mathrm{ppm}$, and $0.02 \mathrm{Da}$ for fragment ions. Mascot data were further imported into Proline v1.4 software ${ }^{75}$. Proteins were validated against a Mascot pretty rank equal to 1 and a 1\% FDR for both peptide spectrum matches (PSM score) and protein sets (Protein Set score). The total number of MS/MS fragmentation spectra was used to quantify each protein from at least three independent 
biological replicates: this "BasicSC" value, calculated by proline, includes all PSMs of all peptides, including modified peptides ( 3 fixed and variable modifications) and the peptides shared by different protein sets. After column-wise normalization of the data matrix, the "BasicSC" spectral count values were submitted to a negative-binomial test using edgeR GLM regression by $R$ ( $R$ v3.2.5). The statistical test was based on the published msmsTests $R$ package available in Bioconductor to process label-free LC-MS/MS data by spectral counts ${ }^{76}$. For each identified protein, an adjusted P-value (adjp), corrected by the Benjamini-Hochberg procedure, was calculated, as well as the protein fold-change (FC). The MS data were deposited in the ProteomeXchange Consortium database via the $\operatorname{PRIDE}^{77}$ partner repository with the dataset identifier: Project accession: PXD028818; Project DOI: 10.6019/PXD028818. Reviewer account details: Username: reviewer_pxd028818@ebi.ac.uk, Password: obn4O3Cj. Table S5 shows the match between the figures, the proteomic files and samples used for the proteomic investigations.

\section{SUPPORTING INFORMATION}

Table summarizing proteomic data obtained previously and in this study; table describing strains used in this study; table describing strains used in this study; table describing plasmids used in this study; 2 tables describing primers used in this study; a table showing the match between the figures, the proteomic files and samples used for the proteomic investigations; growth of PAO1 and $\Delta h a s R \Delta p h u R$ cells in CAA in the absence an presence of hemin; modulation of the transcription of genes encoding TBDTs involved in iron or hemin acquisition in $\Delta h a s R \Delta p h u R$ cells when grown in CAA medium with or without $0.25 \mu \mathrm{M}$ hemin; chemical structures of siderophores used in the study; modulation of the transcription of genes of $P$. aeruginosa PAO1 grown with ENT or with ENT and hemin; modulation of the transcription of genes of $P$. aeruginosa 
PAO1 grown with DFOB or DFPO with hemin; an Excel file with the other proteins having their expression modulated by the growth conditions described in Figure 2, 7 and 9.

\title{
CORRESPONDING AUTHOR INFORMATION
}

To whom correspondence should be addressed: isabelle.schalk@unistra.fr.

\section{AUTHOR CONTRIBUTIONS}

V.N. and I.J.S. conceived the idea and designed the experiments. V.N. performed bacterial cultures, ${ }^{55} \mathrm{Fe}$ uptake assays, siderophore measurements, RT-qPCR assays. L.K. and P.H. performed proteomic assays and analyzes. M.M. and G.L.A.M. synthesized TCV. I.J.S., V.N., L.K. and P.H. wrote the manuscript.

\begin{abstract}
ABBREVIATIONS USED
CAA, casamino acid; CCCP, Carbonyl cyanide-m-chlorophenylhydrazone; DFOB, desferrioxamine B; ENT, enterobactin; NOCA, nocardamine; $\mathrm{PCH}$, pyochelin; PVD, pyoverdine; RT-qPCR, quantitative reverse transcription polymerase chain reaction; TBDT, TonB-dependent transporters; TCV, tris-catechol vector.
\end{abstract}

\begin{abstract}
AKNOWLEDGMENTS
This work was partially funded by the Centre National de la Recherche Scientifique. V Normant held a fellowship from the Fondation pour la Recherche Médicale. The mass spectrometry instrumentation at the IBMC was funded by the University of Strasbourg, IdEx "Equipement
\end{abstract}


mi-lourd" 2015. The equipment at the IPHC was partially funded by the French Proteomics Infrastructure (ProFI; ANR-10-INSB-08-03).

\section{REFERENCES}

(1) Andreini, C.; Bertini, I.; Cavallaro, G.; Holliday, G. L.; Thornton, J. M. Metal Ions in Biological Catalysis: From Enzyme Databases to General Principles. J Biol Inorg Chem 2008, $13(8), 1205-1218$.

(2) Andreini, C.; Bertini, I.; Rosato, A. Metalloproteomes: A Bioinformatic Approach. Acc. Chem. Res. 2009, 42 (10), 1471-1479. https://doi.org/10.1021/ar900015x.

(3) Lopez, C. A.; Skaar, E. P. The Impact of Dietary Transition Metals on Host-Bacterial Interactions. Cell Host Microbe 2018, $23 \quad$ (6), 737-748. https://doi.org/10.1016/j.chom.2018.05.008.

(4) Ratliff, A. C.; Buchanan, S. K.; Celia, H. Ton Motor Complexes. Curr Opin Struct Biol 2021, 67, 95-100. https://doi.org/10.1016/j.sbi.2020.09.014.

(5) Yukl, E. T.; Jepkorir, G.; Alontaga, A. Y.; Pautsch, L.; Rodriguez, J. C.; Rivera, M.; Moenne-Loccoz, P. Kinetic and Spectroscopic Studies of Hemin Acquisition in the Hemophore HasAp from Pseudomonas aeruginosa. Biochemistry 2010, 49 (31), 6646-6654. https://doi.org/10.1021/bi100692f.

(6) Centola, G.; Deredge, D. J.; Hom, K.; Ai, Y.; Dent, A. T.; Xue, F.; Wilks, A. Gallium(III)-Salophen as a Dual Inhibitor of Pseudomonas aeruginosa Heme Sensing and Iron Acquisition. ACS Infect. Dis. 2020, $6 \quad$ (8), 2073-2085. https://doi.org/10.1021/acsinfecdis.0c00138.

(7) Smith, A. D.; Wilks, A. Differential Contributions of the Outer Membrane Receptors PhuR and HasR to Heme Acquisition in Pseudomonas aeruginosa. J. Biol. Chem. 2015, 290 (12), 7756-7766. https://doi.org/10.1074/jbc.M114.633495. 
(8) Smith, A. D.; Modi, A. R.; Sun, S.; Dawson, J. H.; Wilks, A. Spectroscopic Determination of Distinct Heme Ligands in Outer-Membrane Receptors PhuR and HasR of Pseudomonas aeruginosa. Biochemistry 2015, $54 \quad$ (16), $\quad$ 2601-2612. https://doi.org/10.1021/acs.biochem.5b00017.

(9) Dent, A. T.; Brimberry, M.; Albert, T.; Lanzilotta, W. N.; Moënne-Loccoz, P.; Wilks, A. Axial Heme Coordination by the Tyr-His Motif in the Extracellular Hemophore HasAp Is Critical for the Release of Heme to the HasR Receptor of Pseudomonas aeruginosa. Biochemistry 2021. https://doi.org/10.1021/acs.biochem.1c00389.

(10) Ho, W. W.; Li, H.; Eakanunkul, S.; Tong, Y.; Wilks, A.; Guo, M.; Poulos, T. L. Holoand Apo-Bound Structures of Bacterial Periplasmic Heme-Binding Proteins. J Biol Chem 2007, 282 (49), 35796-35802. https://doi.org/10.1074/jbc.M706761200.

(11) Tripathi, S.; O’Neill, M. J.; Wilks, A.; Poulos, T. L. Crystal Structure of the Pseudomonas aeruginosa Cytoplasmic Heme Binding Protein, Apo-PhuS. J. Inorg. Biochem. 2013, 128, 131-136. https://doi.org/10.1016/j.jinorgbio.2013.07.030.

(12) Barker, K. D.; Barkovits, K.; Wilks, A. Metabolic Flux of Extracellular Heme Uptake in Pseudomonas aeruginosa Is Driven by the Iron-Regulated Heme Oxygenase (HemO). J. Biol. Chem. 2012, 287 (22), 18342-18350. https://doi.org/10.1074/jbc.M112.359265.

(13) Mouriño, S.; Giardina, B. J.; Reyes-Caballero, H.; Wilks, A. Metabolite-Driven Regulation of Heme Uptake by the Biliverdin IX $\beta / \delta$-Selective Heme Oxygenase (HemO) of Pseudomonas aeruginosa. J Biol Chem 2016, 291 (39), 20503-20515. https://doi.org/10.1074/jbc.M116.728527.

(14) Dent, A. T.; Mouriño, S.; Huang, W.; Wilks, A. Post-Transcriptional Regulation of the Pseudomonas aeruginosa Heme Assimilation System (Has) Fine-Tunes Extracellular Heme Sensing. J Biol Chem 2019, 294 (8), 2771-2785. https://doi.org/10.1074/jbc.RA118.006185.

(15) Otero-Asman, J. R.; García-García, A. I.; Civantos, C.; Quesada, J. M.; Llamas, M. A. 
Pseudomonas aeruginosa Possesses Three Distinct Systems for Sensing and Using the Host Molecule Haem. Environ. Microbiol. 2019. https://doi.org/10.1111/1462-2920.14773.

(16) Marvig, R. L.; Damkiær, S.; Khademi, S. M. H.; Markussen, T. M.; Molin, S.; Jelsbak, L. Within-Host Evolution of Pseudomonas aeruginosa Reveals Adaptation toward Iron Acquisition from Hemoglobin. mBio 2014, 5 (3), e00966-00914. https://doi.org/10.1128/mBio.00966-14.

(17) Seyedmohammad, S.; Fuentealba, N. A.; Marriott, R. A. J.; Goetze, T. A.; Edwardson, J. M.; Barrera, N. P.; Venter, H. Structural Model of FeoB, the Iron Transporter from Pseudomonas aeruginosa, Predicts a Cysteine Lined, GTP-Gated Pore. Biosci Rep 2016, 36 (2), e00322. https://doi.org/10.1042/BSR20160046.

(18) Gasser, V.; Guillon, L.; Cunrath, O.; Schalk, I. J. Cellular Organization of Siderophore Biosynthesis in Pseudomonas aeruginosa: Evidence for Siderosomes. Journal of inorganic biochemistry 2015, 148, 27-34. https://doi.org/10.1016/j.jinorgbio.2015.01.017.

(19) Schalk, I. J.; Rigouin, C.; Godet, J. An Overview of Siderophore Biosynthesis among Fluorescent Pseudomonads and New Insights into Their Complex Cellular Organization. Environ. Microbiol. 2020, 22 (4), 1447-1466. https://doi.org/10.1111/1462-2920.14937.

(20) Ghysels, B.; Dieu, B. T.; Beatson, S. A.; Pirnay, J. P.; Ochsner, U. A.; Vasil, M. L.; Cornelis, P. FpvB, an Alternative Type I Ferripyoverdine Receptor of Pseudomonas aeruginosa. Microbiology 2004, 150 (Pt 6), 1671-1680.

(21) Brillet, K.; Journet, L.; Celia, H.; Paulus, L.; Stahl, A.; Pattus, F.; Cobessi, D. A $\beta$ Strand Lock-Exchange for Signal Transduction in TonB-Dependent Transducers on the Basis of a Common Structural Motif. Structure 2007, 15, 1383-1391.

(22) Cobessi, D.; Celia, H.; Pattus, F. Crystallization and X-Ray Diffraction Analyses of the Outer Membrane Pyochelin Receptor FptA from Pseudomonas aeruginosa. Acta Crystallogr D Biol Crystallogr 2004, 60 (Pt 10), 1919-1921. 
(23) Greenwald, J.; Hoegy, F.; Nader, M.; Journet, L.; Mislin, G. L. A.; Graumann, P. L.; Schalk, I. J. Real-Time FRET Visualization of Ferric-Pyoverdine Uptake in Pseudomonas aeruginosa: A Role for Ferrous Iron. J Biol Chem 2007, 282, 2987-2995.

(24) Ganne, G.; Brillet, K.; Basta, B.; Roche, B.; Hoegy, F.; Gasser, V.; Schalk, I. J. Iron Release from the Siderophore Pyoverdine in Pseudomonas aeruginosa Involves Three New Actors: FpvC, FpvG, and FpvH. ACS Chem. Biol. 2017, 12 (4), 1056-1065. https://doi.org/10.1021/acschembio.6b01077.

(25) Barber, M. F.; Elde, N. C. Buried Treasure: Evolutionary Perspectives on Microbial Iron Piracy. Trends Genet. 2015, 31 (11), 627-636. https://doi.org/10.1016/j.tig.2015.09.001.

(26) Perraud, Q.; Cantero, P.; Roche, B.; Gasser, V.; Normant, V. P.; Kuhn, L.; Hammann, P.; Mislin, G. L. A.; Ehret-Sabatier, L.; Schalk, I. J. Phenotypic Adaption of Pseudomonas aeruginosa by Hacking Siderophores Produced by Other Microorganisms. Mol. Cell Proteomics 2020, 19 (4), 589-607. https://doi.org/10.1074/mcp.RA119.001829.

(27) Poole, K.; Young, L.; Neshat, S. Enterobactin-Mediated Iron Transport in Pseudomonas aeruginosa. J Bacteriol 1990, 172 (12), 6991-6996.

(28) Ghysels, B.; Ochsner, U.; Mollman, U.; Heinisch, L.; Vasil, M.; Cornelis, P.; Matthijs, S. The Pseudomonas aeruginosa pirA Gene Encodes a Second Receptor for Ferrienterobactin and Synthetic Catecholate Analogues. FEMS Microbiol Lett 2005, 246 (2), 167-174.

(29) Moynié, L.; Luscher, A.; Rolo, D.; Pletzer, D.; Tortajada, A.; Weingart, H.; Braun, Y.; Page, M. G. P.; Naismith, J. H.; Köhler, T. Structure and Function of the PiuA and PirA Siderophore-Drug Receptors from Pseudomonas aeruginosa and Acinetobacter baumannii. Antimicrob. Agents Chemother. 2017, 61 (4). https://doi.org/10.1128/AAC.02531-16.

(30) Moynie, L.; Milenkovic, S.; Malloci, G.; Mislin, G. L. A.; Baco, E.; Gasser, V.; Schalk, I. J.; Ceccarelli, M.; Naismith, J. H. The Complex of Ferric-Enterobactin with Its Transporter 
Suggests a Multi-Step Conformationally Coupled Process of Uptake. Nature Com. 2019, 10 (1), 3673. doi: 10.1038/s41467-019-11508-y

(31) Elias, S.; Degtyar, E.; Banin, E. FvbA Is Required for Vibriobactin Utilization in Pseudomonas aeruginosa. Microbiology 2011, $157 \quad(\mathrm{Pt} \quad 7), \quad 2172-2180$. https://doi.org/10.1099/mic.0.044768-0.

(32) Llamas, M. A.; Sparrius, M.; Kloet, R.; Jimenez, C. R.; Vandenbroucke-Grauls, C.; Bitter, W. The Heterologous Siderophores Ferrioxamine B and Ferrichrome Activate Signaling Pathways in Pseudomonas aeruginosa. J Bacteriol 2006, 188 (5), 1882-1891.

(33) Josts, I.; Veith, K.; Tidow, H. Ternary Structure of the Outer Membrane Transporter FoxA with Resolved Signalling Domain Provides Insights into TonB-Mediated Siderophore Uptake. eLife 2019, 8, e48528. https://doi.org/10.7554/eLife.48528.

(34) Hannauer, M.; Barda, Y.; Mislin, G. L.; Shanzer, A.; Schalk, I. J. The Ferrichrome Uptake Pathway in Pseudomonas aeruginosa Involves an Iron Release Mechanism with Acylation of the Siderophore and a Recycling of the Modified Desferrichrome. $J$ Bacteriol 2010, 192, 1212-1220. https://doi.org/10.1128/JB.01539-09.

(35) Normant, V.; Josts, I.; Kuhn, L.; Perraud, Q.; Fritsch, S.; Hammann, P.; Mislin, G. L. A.; Tidow, H.; Schalk, I. J. Nocardamine-Dependent Iron Uptake in Pseudomonas aeruginosa: Exclusive Involvement of the FoxA Outer Membrane Transporter. ACS Chem. Biol. 2020. https://doi.org/10.1021/acschembio.0c00535.

(36) Llamas, M. A.; Mooij, M. J.; Sparrius, M.; Vandenbroucke-Grauls, C. M.; Ratledge, C.; Bitter, W. Characterization of Five Novel Pseudomonas aeruginosa Cell-Surface Signalling Systems. Mol Microbiol 2008, 67 (2), 458-472.

(37) Cuiv, P. O.; Clarke, P.; O’Connell, M. Identification and Characterization of an IronRegulated Gene, ChtA, Required for the Utilization of the Xenosiderophores Aerobactin, Rhizobactin 1021 and Schizokinen by Pseudomonas aeruginosa. Microbiology 2006, 152 (Pt 
4), 945-954. https://doi.org/10.1099/mic.0.28552-0.

(38) Marshall, B.; Stintzi, A.; Gilmour, C.; Meyer, J.-M.; Poole, K. Citrate-Mediated Iron Uptake in Pseudomonas aeruginosa: Involvement of the Citrate-Inducible FecA Receptor and the FeoB Ferrous Iron Transporter. Microbiology (Reading, Engl.) 2009, 155 (Pt 1), 305-315. https://doi.org/10.1099/mic.0.023531-0.

(39) Dean, C. R.; Poole, K. Expression of the Ferric Enterobactin Receptor (PfeA) of Pseudomonas aeruginosa: Involvement of a Two-Component Regulatory System. Mol Microbiol 1993, 8 (6), 1095-1103.

(40) Michel, L.; Gonzalez, N.; Jagdeep, S.; Nguyen-Ngoc, T.; Reimmann, C. PchR-Box Recognition by the AraC-Type Regulator PchR of Pseudomonas aeruginosa Requires the Siderophore Pyochelin as an Effector. Mol Microbiol 2005, 58 (2), 495-509.

(41) Perraud, Q.; Kuhn, L.; Fritsch, S.; Graulier, G.; Gasser, V.; Normant, V.; Hammann, P.; Schalk, I. J. Opportunistic Use of Catecholamine Neurotransmitters as Siderophores to Access Iron by Pseudomonas aeruginosa. Environ Microbiol 2020. https://doi.org/10.1111/14622920.15372 .

(42) Hijazi, S.; Visca, P.; Frangipani, E. Gallium-Protoporphyrin IX Inhibits Pseudomonas aeruginosa Growth by Targeting Cytochromes. Front Cell Infect Microbiol 2017, 7, 12. https://doi.org/10.3389/fcimb.2017.00012.

(43) Mislin, G. L. A.; Schalk, I. J. Siderophore-Dependent Iron Uptake Systems as Gates for Antibiotic Trojan Horse Strategies against Pseudomonas aeruginosa. Metallomics 2014, 6 (3), 408-420. https://doi.org/10.1039/c3mt00359k.

(44) Schalk, I. J.; Mislin, G. L. A. Bacterial Iron Uptake Pathways: Gates for the Import of Bactericide Compounds. J. Med. Chem. 2017, 60 (11), 4573-4576. https://doi.org/10.1021/acs.jmedchem.7b00554.

(45) Perraud, Q.; Cantero, P.; Munier, M.; Hoegy, F.; Zill, N.; Gasser, V.; Mislin, G. L. A.; 
Ehret-Sabatier, L.; Schalk, I. J. Phenotypic Adaptation of Pseudomonas aeruginosa in the Presence of Siderophore-Antibiotic Conjugates during Epithelial Cell Infection. Microorganisms 2020, 8 (11). https://doi.org/10.3390/microorganisms8111820.

(46) Syed, Y. Y. Cefiderocol: A Review in Serious Gram-Negative Bacterial Infections. Drugs 2021, 81 (13), 1559-1571. https://doi.org/10.1007/s40265-021-01580-4.

(47) Silva, A. M.; Kong, X.; Parkin, M. C.; Cammack, R.; Hider, R. C. Iron(III) Citrate Speciation in Aqueous Solution. Dalton Trans 2009, 40, 8616-8625.

(48) Takase, H.; Nitanai, H.; Hoshino, K.; Otani, T. Impact of Siderophore Production on Pseudomonas aeruginosa Infections in Immunosuppressed Mice. Infect Immun 2000, 68 (4), $1834-1839$.

(49) Konings, A. F.; Martin, L. W.; Sharples, K. J.; Roddam, L. F.; Latham, R.; Reid, D. W.; Lamont, I. L. Pseudomonas aeruginosa Uses Multiple Pathways to Acquire Iron during Chronic Infection in Cystic Fibrosis Lungs. Infect Immun 2013, 81 (8), 2697-2704. https://doi.org/10.1128/IAI.00418-13.

(50) Nguyen, A. T.; O’Neill, M. J.; Watts, A. M.; Robson, C. L.; Lamont, I. L.; Wilks, A.; Oglesby-Sherrouse, A. G. Adaptation of Iron Homeostasis Pathways by a Pseudomonas aeruginosa Pyoverdine Mutant in the Cystic Fibrosis Lung. J Bacteriol 2014, 196 (12), 22652276. https://doi.org/10.1128/JB.01491-14.

(51) Marvig, R. L.; Sommer, L. M.; Molin, S.; Johansen, H. K. Convergent Evolution and Adaptation of Pseudomonas aeruginosa within Patients with Cystic Fibrosis. Nat Genet 2015, 47 (1), 57-64. https://doi.org/10.1038/ng.3148.

(52) Rossi, E.; La Rosa, R.; Bartell, J. A.; Marvig, R. L.; Haagensen, J. A. J.; Sommer, L. M.; Molin, S.; Johansen, H. K. Pseudomonas aeruginosa Adaptation and Evolution in Patients with Cystic Fibrosis. Nat Rev Microbiol 2021, 19 (5), 331-342. https://doi.org/10.1038/s41579020-00477-5. 
(53) Cunrath, O.; Geoffroy, V. A.; Schalk, I. J. Metallome of Pseudomonas aeruginosa: A Role for Siderophores. Environ. Microbiol. 2016, 18 (10), 3258-3267. https://doi.org/10.1111/1462-2920.12971.

(54) Lhospice, S.; Gomez, N. O.; Ouerdane, L.; Brutesco, C.; Ghssein, G.; Hajjar, C.; Liratni, A.; Wang, S.; Richaud, P.; Bleves, S.; Ball, G.; Borezée-Durant, E.; Lobinski, R.; Pignol, D.; Arnoux, P.; Voulhoux, R. Pseudomonas aeruginosa Zinc Uptake in Chelating Environment Is Primarily Mediated by the Metallophore Pseudopaline. Sci Rep 2017, 7 (1), 17132. https://doi.org/10.1038/s41598-017-16765-9.

(55) Reddi, A. R.; Hamza, I. Heme Mobilization in Animals: A Metallolipid's Journey. Acc Chem Res 2016, 49 (6), 1104-1110. https://doi.org/10.1021/acs.accounts.5b00553.

(56) Biville, F.; Cwerman, H.; Létoffé, S.; Rossi, M.-S.; Drouet, V.; Ghigo, J. M.; Wandersman, C. Haemophore-Mediated Signalling in Serratia marcescens: A New Mode of Regulation for an Extra Cytoplasmic Function (ECF) Sigma Factor Involved in Haem Acquisition. Mol Microbiol 2004, 53 (4), 1267-1277. https://doi.org/10.1111/j.13652958.2004.04207.x.

(57) Imperi, F.; Tiburzi, F.; Visca, P. Molecular Basis of Pyoverdine Siderophore Recycling in Pseudomonas aeruginosa. Proc. Natl. Acad. Sci. U. S. A 2009, 106 (48), 20440-20445. https://doi.org/10.1073/pnas.0908760106.

(58) Hannauer, M.; Yeterian, E.; Martin, L. W.; Lamont, I. L.; Schalk, I. J. Secretion of Newly Synthesized Pyoverdine by Pseudomonas aeruginosa Involves an Efflux Pump. FEBS Lett 2010, 584 (23), 4751-4755.

(59) Yeterian, E.; Martin, L. W.; Lamont, I. L.; Schalk, I. J. An Efflux Pump Is Required for Siderophore Recycling by Pseudomonas aeruginosa. Environ Microbiol Report 2010, 2 (3), 412-418. https://doi.org/10.1016/j.febslet.2010.10.051.

(60) Vasil, M. L. How We Learnt about Iron Acquisition in Pseudomonas aeruginosa: A 
Series of Very Fortunate Events. Biometals 2007, 20 (3-4), 587-601. https://doi.org/10.1007/s10534-006-9067-2.

(61) Wei, Q.; Minh, P. N. L.; Dötsch, A.; Hildebrand, F.; Panmanee, W.; Elfarash, A.; Schulz, S.; Plaisance, S.; Charlier, D.; Hassett, D.; Häussler, S.; Cornelis, P. Global Regulation of Gene Expression by OxyR in an Important Human Opportunistic Pathogen. Nucleic Acids Res 2012, 40 (10), 4320-4333. https://doi.org/10.1093/nar/gks017.

(62) Reen, F. J.; Haynes, J. M.; Mooij, M. J.; O’Gara, F. A Non-Classical LysR-Type Transcriptional Regulator PA2206 Is Required for an Effective Oxidative Stress Response in Pseudomonas aeruginosa. PLoS One 2013, $8 \quad$ (1), e54479. https://doi.org/10.1371/journal.pone.0054479.

(63) Troxell, B.; Hassan, H. M. Transcriptional Regulation by Ferric Uptake Regulator (Fur) in Pathogenic Bacteria. Front Cell Infect Microbiol 2013, 3, 59. https://doi.org/10.3389/fcimb.2013.00059.

(64) Vinckx, T.; Matthijs, S.; Cornelis, P. Loss of the Oxidative Stress Regulator OxyR in Pseudomonas aeruginosa PAO1 Impairs Growth under Iron-Limited Conditions. FEMS Microbiol Lett 2008, 288 (2), 258-265. https://doi.org/10.1111/j.1574-6968.2008.01360.x.

(65) Cunrath, O.; Graulier, G.; Carballido-Lopez, A.; Pérard, J.; Forster, A.; Geoffroy, V. A.; Saint Auguste, P.; Bumann, D.; Mislin, G. L. A.; Michaud-Soret, I.; Schalk, I. J.; Fechter, P. The Pathogen Pseudomonas aeruginosa Optimizes the Production of the Siderophore Pyochelin upon Environmental Challenges. Metallomics 2020, 12 (12), 2108-2120. https://doi.org/10.1039/d0mt00029a.

(66) Clément, E.; Mesini, P. J.; Pattus, F.; Abdallah, M. A.; Schalk, I. J. The Binding Mechanism of Pyoverdin with the Outer Membrane Receptor FpvA in Pseudomonas aeruginosa Is Dependent on Its Iron-Loaded Status. Biochemistry 2004, 43, 7954-7965.

(67) Gasser, V.; Baco, E.; Cunrath, O.; August, P. S.; Perraud, Q.; Zill, N.; Schleberger, C.; 
Schmidt, A.; Paulen, A.; Bumann, D.; Mislin, G. L. A.; Schalk, I. J. Catechol Siderophores Repress the Pyochelin Pathway and Activate the Enterobactin Pathway in Pseudomonas aeruginosa: An Opportunity for Siderophore-Antibiotic Conjugates Development. Environ. Microbiol. 2016, 18 (3), 819-832. https://doi.org/10.1111/1462-2920.13199.

(68) Perraud, Q.; Moynié, L.; Gasser, V.; Munier, M.; Godet, J.; Hoegy, F.; Mély, Y.; Mislin, G. L. A.; Naismith, J. H.; Schalk, I. J. A Key Role for the Periplasmic PfeE Esterase in Iron Acquisition via the Siderophore Enterobactin in Pseudomonas aeruginosa. ACS Chem. Biol. 2018, 13 (9), 2603-2614. https://doi.org/10.1021/acschembio.8b00543.

(69) Cornelis, P.; Dingemans, J. Pseudomonas Aeruginosa Adapts Its Iron Uptake Strategies in Function of the Type of Infections. Front Cell Infect Microbiol 2013, 3, 75. https://doi.org/10.3389/fcimb.2013.00075.

(70) Meyer, J. M.; Abdallah, M. A. The Fluorescent Pigment of Pseudomonas Fluorescens: Biosynthesis, Purification and Physicochemical Properties. J Gen Microbiol 1978, 107, 319328.

(71) Demange, P.; Wendenbaum, S.; Linget, C.; Mertz, C.; Cung, M. T.; Dell, A., Abdallah, M. A. Bacterial Siderophores: Structure and NMR Assigment of Pyoverdins PaA, Siderophores of Pseudomonas aeruginosa ATCC 15692. Biol. Metals 1990, 3, 155-170.

(72) Zamri, A.; Abdallah, M. A. An Improved Stereocontrolled Synthesis of Pyochelin, a Siderophore of Pseudomonas aeruginosa and Burkholderia cepacia. Tetrahedron 2000, 56, $249-256$.

(73) Hoegy, F.; Schalk, I. J. Monitoring Iron Uptake by Siderophores. Methods Mol Biol 2014, 1149, 337-346. https://doi.org/10.1007/978-1-4939-0473-0_28.

(74) Hoegy, F.; Mislin, G. L.; Schalk, I. J. Pyoverdine and Pyochelin Measurements. Methods Mol Biol 2014, 1149, 293-301. https://doi.org/10.1007/978-1-4939-0473-0_24.

(75) Bouyssié, D.; Hesse, A.-M.; Mouton-Barbosa, E.; Rompais, M.; Macron, C.; Carapito, 
C.; Gonzalez de Peredo, A.; Couté, Y.; Dupierris, V.; Burel, A.; Menetrey, J.-P.; Kalaitzakis, A.; Poisat, J.; Romdhani, A.; Burlet-Schiltz, O.; Cianférani, S.; Garin, J.; Bruley, C. Proline: An Efficient and User-Friendly Software Suite for Large-Scale Proteomics. Bioinformatics 2020, 36 (10), 3148-3155. https://doi.org/10.1093/bioinformatics/btaa118.

(76) Gregori, J.; Sanchez, A.; Villanueva, J. MsmsTests: LC-MS/MS Differential Expression Tests; Bioconductor version: Release (3.9), 2019. https://doi.org/10.18129/B9.bioc.msmsTests. (77) Vizcaíno, J. A.; Csordas, A.; del-Toro, N.; Dianes, J. A.; Griss, J.; Lavidas, I.; Mayer, G.; Perez-Riverol, Y.; Reisinger, F.; Ternent, T.; Xu, Q.-W.; Wang, R.; Hermjakob, H. 2016 Update of the PRIDE Database and Its Related Tools. Nucleic Acids Res. 2016, 44 (D1), D447456. https://doi.org/10.1093/nar/gkv1145. 
Iron sources: Hemin + xenosiderophores

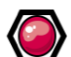

10

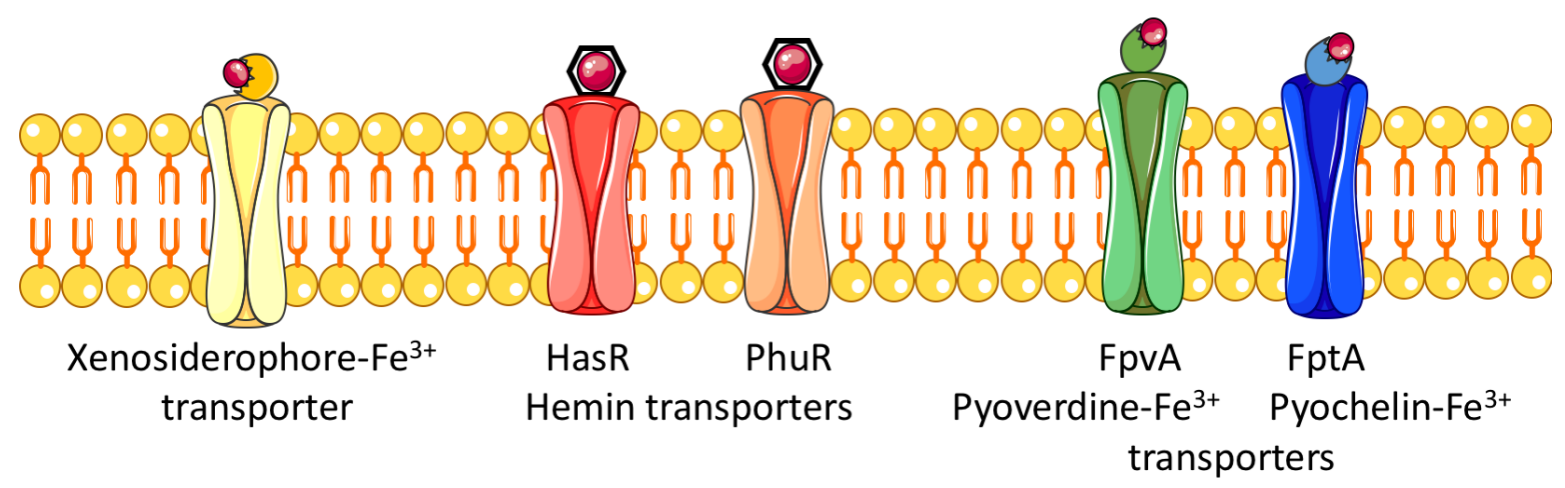

Transporters present in $P$. aeruginosa outer membrane

Detected by differential proteomics and RT-qPCR 